\title{
Co-Delivery Of Dihydroartemisinin And HMGBI siRNA By TAT-Modified Cationic Liposomes Through The TLR4 Signaling Pathway For Treatment Of Lupus Nephritis
}

This article was published in the following Dove Press journal:

International Journal of Nanomedicine

\section{Lu Diao $\mathbb{D}^{1,2}$ \\ Jin Tao $\mathbb{1}^{2}$ \\ Yiqi Wang ${ }^{3}$ \\ Ying $\mathrm{Hu}^{1,2}$ \\ Wenfei $\mathrm{He}^{\mathrm{I}}$}

'School of Pharmaceutical Sciences, Wenzhou Medical University, Wenzhou, Zhejiang 325035, People's Republic of China; ${ }^{2}$ College of Pharmacy, Zhejiang Pharmaceutical College, Ningbo, Zhejiang 3I5I00, People's Republic of China; ${ }^{3}$ College of Pharmaceutical Sciences, Zhejiang Chinese Medical University, Hangzhou, Zhejiang 31/402, People's Republic of China
Correspondence: Ying $\mathrm{Hu}$

College of Pharmacy, Zhejiang

Pharmaceutical College, No. 888, East Section, Yinxian Main Road, The Zone of Higher Education, Ningbo, Zhejiang 315100 , People's Republic of China

Tel +86 57488222707

Fax +865748822 3023

Email pharmhawk@I26.com

Wenfei He

School of Pharmaceutical Sciences, Wenzhou Medical University, Ouhai District, Chashan Street, University Campus, Wenzhou, Zhejiang 325035

People's Republic of Chin

Tel +86057786699572

Email wenfeihe@।26.com
Background and purpose: Systemic lupus erythematous (SLE) is an autoimmune disease caused by many factors. Lupus nephritis (LN) is a common complication of SLE and represents a major cause of morbidity and mortality. Previous studies have shown the advantages of multitargeted therapy for LN and that TLR4 signaling is a target of anti-LN drugs. High-mobility group box 1 (HMGB1), a nuclear protein with a proinflammatory cytokine activity, binds specifically to TLR4 to induce inflammation. We aimed to develop PEGylated TAT peptide-cationic liposomes (TAT-CLs) to deliver anti-HMGB1 siRNA and dihydroartemisinin (DHA) to increase LN therapeutic efficiency and explore their treatment mechanism.

Methods: We constructed the TAT-CLs-DHA/siRNA delivery system using the thin film hydration method. The uptake and localization of Cy3-labeled siRNA were detected by confocal microscopy and flow cytometry. MTT assays were used to detect glomerular mesangial cell proliferation. Real-time PCR, Western blot analysis, and ELISA evaluated the anti-inflammatory mechanism of TAT-CLs-DHA/siRNA.

Results: We constructed the TAT-CLs-DHA/siRNA delivery system measuring approximately $140 \mathrm{~nm}$ with superior storage and serum stabilities. In vitro, it showed significantly greater uptake compared with unmodified liposomes and significant inhibition of glomerular mesangial cell proliferation. TAT-CLs-DHA/siRNA inhibited NF- $\mathrm{BB}$ activation in a concentration-dependent manner. Real-time PCR and Western blot analysis showed that TAT-CLs-DHA/siRNA downregulated expression of HMGB1 mRNA and protein. TAT-CLs-DHA/siRNA markedly diminished Toll-like receptor 4 (TLR4) expression and subsequent activation of MyD88, IRAK4, and NF- $\kappa$ B. Conclusion: TAT-CLs-DHA/siRNA may have the potential for treatment of inflammatory diseases such as LN mediated by the TLR4 signaling pathway.

Keywords: cationic liposome, HMGB1 siRNA, DHA, Toll-like receptor 4

\section{Introduction}

Systemic lupus erythematosus (SLE) is a common multisystem autoimmune disease characterized by immune system dysfunction and excessive inflammatory responses in various organs. ${ }^{1}$ Patients often produce large amounts of autoantibodies, and immune complexes accumulate in the kidneys. Thus, lupus nephritis (LN) is a severe consequence of SLE and a major driver of mortality in SLE patients. ${ }^{2}$

Multi-targeted therapy is an effective treatment for LN. ${ }^{3}$ Excessive activation of the TLR4 signaling pathway is closely related to SLE activity and LN development. ${ }^{4}$ In this 
regard, combinations of two or more therapeutic strategies with different mechanisms are being developed as a promising treatment modality for LN therapy.

Dihydroartemisinin (DHA), a metabolite of artemisinin, has prominent anti-malarial effects. ${ }^{5}$ Recently, a study reported that DHA also possessed potent anti-inflammatory and immunoregulatory properties. ${ }^{6}$ Furthermore, artemisinin derivative SM934 alleviates lupus in MRL/lpr mice by inhibiting B cell activation triggered by MyD88-dependent Toll-like receptor (TLR) signaling. ${ }^{7}$ DHA also ameliorates lupus symptoms in BXSB mice by downregulating the TLR4 signaling pathway. ${ }^{8}$ However, the single target of traditional antimalarial artemisinin drugs limits its application for the treatment of autoimmune diseases. ${ }^{9}$ To date, many studies have indicated that combined administration can achieve multi-targeted treatment. ${ }^{10,11}$

Small interfering RNAs (siRNA) have attracted considerable attention because of their potential therapeutic applications. ${ }^{12}$ High-mobility group box 1 (HMGB1), a nuclear protein with a proinflammatory cytokine activity and ability to stimulate cytokine release, binds specifically to TLR4, the main receptor in the proinflammatory cascade of HMGB1. ${ }^{13}$ HMGB1 expression increases in the renal tissues of mice with SLE. HMGB1 also participates in antibody-induced kidney damage of SLE patients. ${ }^{14}$ Therefore, silencing the HMGB1 gene by siRNA might be a promising strategy for treatment of LN. Thus, a combination of DHA and HMGB1 siRNA might be used to treat $\mathrm{LN}$.

The therapeutic potential of siRNA has considerable obstacles because of its lability, poor membrane permeability, enzymatic degradation, fast systemic clearance, and immunogenicity. ${ }^{15}$ Similarly, DHA is difficult to dissolve in water and cannot reach an effective blood concentration. Therefore, siRNA stabilization in systemic circulation and promotion of effective DHA delivery to kidney tissue is desired. Many approaches, including lipid-based delivery systems, polycationic polymers, nanoparticles, and conjugates, have been developed. ${ }^{16}$ Among these various types of delivery systems, liposomes have attracted considerable attention. Liposomes protect siRNA from RNase degradation, prolong their systemic circulation, and reduce the adverse effects of drugs. ${ }^{17}$

We investigated the TLR4 signaling axis to treat LN by the synergistic effects of DHA and siRNA. We designed a novel cationic liposome delivery system to co-deliver DHA and HMGB1 siRNA. TAT was modified on the liposomal surface to achieve desirable permeability. TAT peptide is a frequently used cell-penetrating peptide and powerful internalization moiety that has been widely used to modify drug delivery systems. The aim of this study was to increase the therapeutic efficiency of DHA by codelivery with HMGB1 siRNA (Scheme 1). After preparing TAT-CLs-DHA/siRNA and characterizing their cellular uptake, gene silencing and cytotoxicity, inhibition of MMC cell proliferation, and the TLR4 inflammatory pathway were investigated to determine the efficiency and safety of co-delivery of HMGB1 siRNA and DHA. Our study provides the proof-of-concept for TAT-CLs-DHA/ siRNA as an effective platform to mediate the release of a drug for therapy of LN via the TLR4 signaling axis, leading to anti-inflammatory effects.

\section{Materials And Methods Materials}

1,2-Dioleoyl-3-trimethylammonium-propane (DOTAP) was purchased from Cardenpharma Switzerland LLC (Liestal, Switzerland). Cholesterol, Ham's F12 nutrient medium, high glucose DMEM, fetal bovine serum (FBS), and lipopolysaccharide from Escherichia coli 055:B5 were purchased from Sigma Chemicals Co. (St. Louis, MO, USA). Maleimide derivatized PEG2000-DSPE (Mal-PEG2000DSPE) was purchased from Avanti Polar Lipids (Alabaster, AL, USA). TAT peptide with a terminated cysteine (CysTAT, AYGRKKRRQRRR; MW: 1734) was synthesized by Guoping Pharmaceutical Corporation (Hefei, Anhui, China). DHA was obtained from the ZheJiang Institute for Food and Drug Control (Hangzhou, Zhejiang Province, China). AntiHMGB1, -MyD88, and -NF-кB antibodies were purchased from Abcam (Cambridge, UK). Anti-TLR4 and -IRAK4 antibodies were purchased from Cell Signaling Technology (Beverly, MA). 2-(4-amidinophenyl)-6-indolecarbamidine dihydrochloride (DAPI) was purchased from Beyotime Biotechnology (Hangzhou, Zhejiang, China). Cy3-labeled NC siRNA and negative control siRNA (NC) were synthesized by GenePharma (Shanghai, China). HMBG1 siRNA and TRIzol reagent were purchased from Thermo Fisher (Waltham, Massachusetts, USA). HEK-Blue Selection and QUANTI-Blue solution were purchased from Invivogen (San Diego, CA, USA).

\section{Cell Lines}

The glomerular mesangial cell line MMC was obtained from the Chinese Academy of Sciences, Shanghai Institute for Biological Sciences Cell Resource Center. Cells were cultured in DMEM/F12 (3:1) medium supplemented with 10\% 


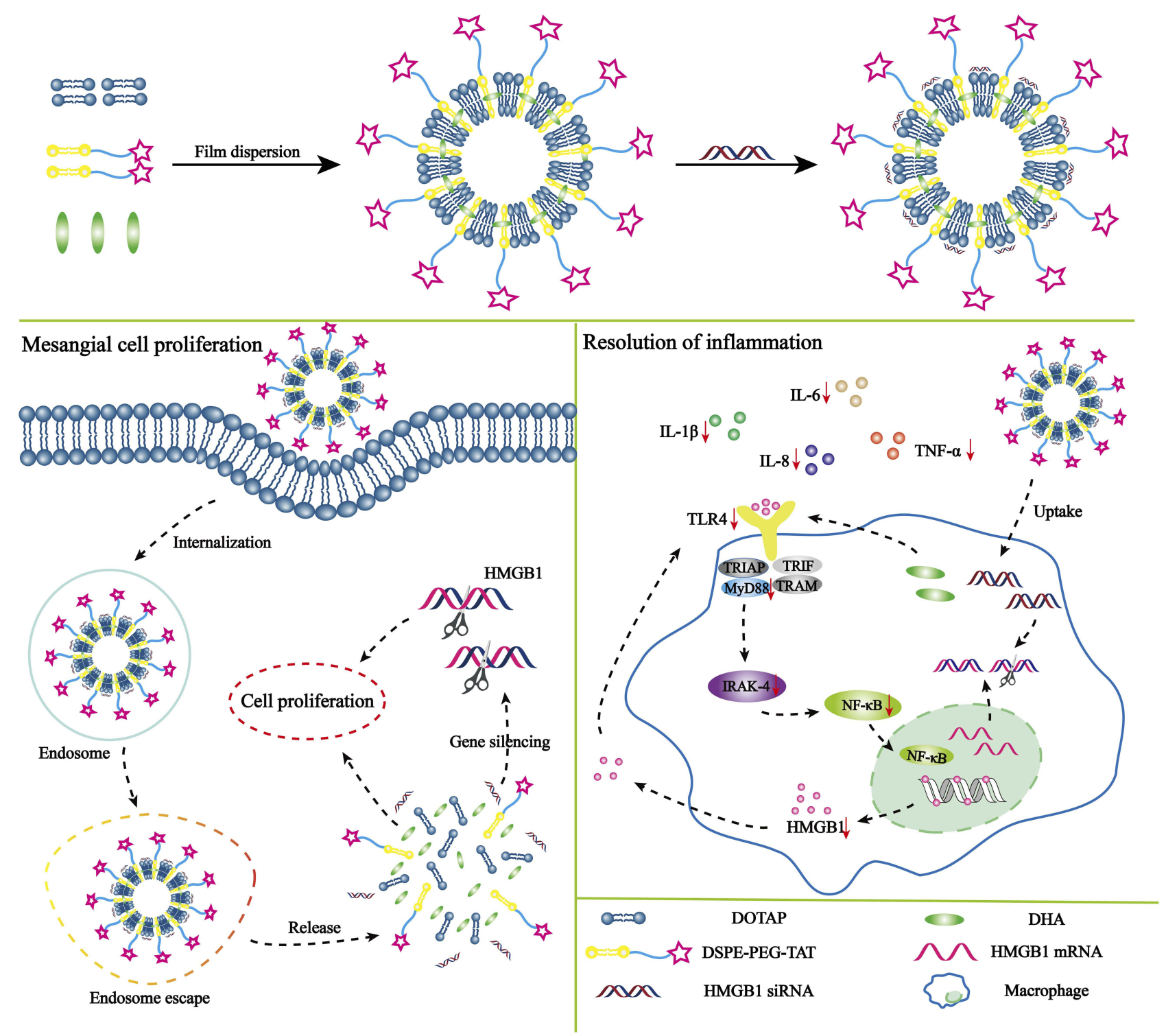

Scheme I Structure and treatment strategy of TAT-CLs-DHA/siRNA. The mechanism of TAT-CLs-DHA/siRNA is to inhibit the TLR4 signaling pathway to therapy LN. The therapy was based on a synergistic effect involving the HMGBI siRNA and DHA which the siRNA binds to HMGBI mRNA and the DHA act on the TLR4 signal pathway of immune cell.

fetal bovine serum, penicillin, and streptomycin in a humidified atmosphere of $5 \% \mathrm{CO}_{2}$ at $37^{\circ} \mathrm{C}$. HEK-Blue ${ }^{\mathrm{TM}}$-hTLR4 cells were kindly provided by Professor Thomas C. Mitchell (University of Louisville, USA) and RAW264.7 cells were kindly provided by Assistant Professor Qi yi Wang (Zhejiang Chinese Medical University, China). These two cell lines were cultured in DMEM supplemented with $10 \%$ FBS, penicillin, and streptomycin at $37^{\circ} \mathrm{C}$ with $5 \% \mathrm{CO} 2$. The gifted cells, HEK-BlueTM-hTLR4 and RAW264.7 we used in this study were approved by the institutional review board of Zhejiang Chinese Medical University.

\section{DSPE-PEG2000-TAT Synthesis}

DSPE-PEG2000-TAT was synthesized as described previously. ${ }^{18}$ Briefly, DSPE-PEG2000-Mal and Cys-TAT (molar ratio $=1.5: 1)$ were reacted in $9 \mathrm{~mL}$ of a mixture of $\mathrm{CHCL} 3 / \mathrm{MeOH}(\mathrm{V}: \mathrm{V}=2: 1)$ with gentle stirring in the dark at room temperature for about $20 \mathrm{~h}$. The reaction mixture was protected by nitrogen, and the reaction mixture was evaporated by rotary evaporation under a vacuum. The thin film was then hydrated by ultrapure water in a bath-type sonicator. Finally, the freeze-dried product was stored at $-20^{\circ} \mathrm{C} .1 \mathrm{H}-$ NMR was used to verify successful synthesis of the product. 


\section{TAT-CLs-DHA Preparation}

PEGylated DOTAP/Chol cationic liposomes were prepared as described previously. ${ }^{19}$ Cationic liposomes consisting of DOTAP, Chol, and DSPE-PEG2000-TAT (molar ratio $=2: 1: 0.15)$ were prepared using the thin film hydration method. Briefly, total lipids and DHA were dissolved in $\mathrm{CHCL}_{3}$ and dried to a thin film by rotary evaporation followed by drying in a vacuum at $40^{\circ} \mathrm{C}$. The lipid film was then hydrated by PBS ( $\mathrm{pH}$ 7.4). After sufficient hydration, the liposomes were extruded through a polycarbonate membrane (from 200 to $100 \mathrm{~nm}$ ) 20 times using an extruder to obtain nanosized liposomes.

\section{TAT-CLs-DHA/siRNA Preparation}

TAT-CLs-DHA/siRNA were prepared at a weight ratio of DOTAP:siRNA (15:1) in DEPC-treated $\mathrm{H} 2 \mathrm{O}$ by adding a solution of TAT-CLs-DHA to a prepared siRNA solution. An optimized concentration of siRNA was mixed with liposomes and incubated for $30 \mathrm{~min}$ at room temperature.

\section{Liposome Characterization}

\section{Morphology, Particle Size And Zeta Potential}

The morphology of liposomes was determined by TEM (JEOL2010F, Tokyo, Japan). Briefly, samples were prepared by placing one drop of liposome dispersion onto a copper grid with a carbon membrane, and then staining with $2 \%(w / v)$ uranyl acetate. The liposomes were visualized under a transmission electron microscope operated at $200 \mathrm{KV}$.

After the liposomes and siRNA complexes were dispersed in deionized water, their particle size and zeta potential were measured at $25^{\circ} \mathrm{C}$ using a Zetasizer Nano ZS90 instrument (Malvern Instruments, Worcestershire, UK). Each parameter was measured four times, and then the mean values and standard deviations were calculated.

\section{Evaluation Of siRNA Encapsulation Efficiency (EE\%)}

Agarose gel electrophoresis was used to evaluate siRNA loading in liposomes. The siRNA/liposome complexes were prepared at DOTAP:siRNA ratios ranging from 0 to $40(\mathrm{w} / \mathrm{w})$, before being applied to a $2 \%(\mathrm{w} / \mathrm{v})$ agarose gel in TAE buffer with RNA loading buffer. Images were obtained using a UV transilluminator and digital imaging system (Chemi Doc XRS with Image lab software, BIORAD, USA).

\section{siRNA Serum Stability}

Serum stability of siRNAs encapsulated in cationic liposomes was characterized by agarose gel electrophoresis.
Samples of siRNA or liposome/siRNA complexes were mixed with an equal volume of fresh serum to reach a $50 \%$ serum concentration. At various incubation timepoints $(3,6,12,24,36,48$, and $60 \mathrm{~h})$, each sample with liposomes dissolved by Triton-X 100 was applied to a $2 \%$ $(w / v)$ agarose gel in TAE buffer. The complexes were electrophoresed for $20 \mathrm{~min}$ at $100 \mathrm{~V}$, and the electrophoretic mobility was determined to visualize intact siRNA.

\section{Cell Viability Analysis}

The cytotoxic effect of the blank liposome carrier (TAT-CLs) on MMC, RAW264.7, and HEK-Blue ${ }^{\text {TM}}$-hTLR4 cells was measured by MTT assays. MMC, RAW264.7, and HEKBlue ${ }^{\text {TM}}$-hTLR4 cells were seeded at a density of $1 \times 10^{4}$ cells/well in a 96-well plate and cultured overnight. Then, the cells were treated with various TAT-CL concentrations according to the DOTAP content in liposomes for $24 \mathrm{~h}$. The absorbance of DMSO-solubilized formazan crystals was measured at $490 \mathrm{~nm}$ using a microplate reader.

\section{In Vitro Cell Uptake Assessment Flow Cytometry}

RAW264.7 and MMC cells were seeded at a density of $5 \times$ $10^{5}$ cells per well in 24-well plates and cultured overnight. The above prepared liposomes entrapping Cy3-siRNA were incubated with the cells (final siRNA concentration: $100 \mathrm{nM}$ ) for $4 \mathrm{~h}$. The medium was then removed and the cells were washed three times with cold PBS. The mean fluorescence intensity was analyzed by flow cytometry (BD Biosciences, CA, USA). The uptake kinetics was examined in MMC cells treated with liposomes containing Cy3-siRNA for $0.5,1.0,2.0$, and $4.0 \mathrm{~h}$. Quantitative analysis was conducted by flow cytometry.

\section{Confocal Microscopy}

RAW264.7 and MMC cells were seeded onto 6-well plates at a density of $2 \times 10^{5}$ cells/well and cultured overnight. Then, the cells were transfected with Cy3-labeled CLs-siRNA or TAT-CLs-siRNA at30, 60, 120, and $240 \mathrm{~min}$. After transfection, the cells were washed three times with PBS and fixed with $4 \%$ paraformaldehyde for $20 \mathrm{~min}$. The cells were then washed three times with PBS. Cells were stained with DAPI for $10 \mathrm{~min}$, and images were captured by confocal laser scanning microscopy (FV-1000; Olympus, Australia).

\section{Cell Proliferation Assay}

To investigate the effect of lipopolysaccharide (LPS) on cell proliferation, MMC cells were seeded into 96-well plates at a 
density of $3 \times 10^{3}$ cells/well and cultured for $24 \mathrm{~h}$. The medium was then changed to DMEM with $1 \%$ FBS to induce synchronization at G0 phase. After $24 \mathrm{~h}$, the cells were treated with various concentrations of LPS $(0.5,1,2,3,5,7$ or $10 \mu \mathrm{g} / \mathrm{mL}$ ) to stimulate proliferation. We used an optimal concentration of LPS, which stimulated MMC cell proliferation to the greatest extent. Experimental groups included DHA, Cls-DHA, Cls-DHA/siRNA, and TAT-CLs-DHA/ siRNA. Cells were incubated for a further $24 \mathrm{~h}$ and then proportion of viable cells was measured by MTT assays.

\section{TLR4 Activation Assay}

The concentration-response curve of LPS-induced TLR4 activation was evaluated using HEK-Blue ${ }^{\text {TM}}-$ hTLR4 cells. The cells were plated at $1 \times 10^{5}$ cells/well and various concentrations of LPS were added simultaneously to activate the TLR4 signaling pathway. Cells were then treated for $24 \mathrm{~h}$ with various formulations including DHA, CLssiRNA, CLs-DHA, CLs-DHA/siRNA, and TAT-CLsDHA/siRNA. LPS is a TLR4 agonist that activates TLR4 to induce NF- $\kappa \mathrm{B}$ activation and then induces the secretion of embryonic alkaline phosphatase. Embryonic alkaline phosphatase levels were determined using HEK-Blue ${ }^{\mathrm{TM}}$ Detection medium was analyzed by a Tecan Infinite F200 plate reader (Männedorf, Switzerland) at $630 \mathrm{~nm}$.

\section{Quantitative Real-Time Polymerase Chain Reaction (qRT-PCR)}

Expression of HMGB1, TLR4, MyD88, IRAK4, and NFкB in RAW264.7 cells was measured by quantitative reverse transcription-polymerase chain reaction (qRTPCR). In brief, cells were treated with DHA, CLs-DHA, CLs-siRNA, CLs-DHA/siRNA, and TAT-CLs-DHA/ siRNA during LPS stimulation for $24 \mathrm{~h}$, and then total RNA was extracted from the cells using TRIzol reagent (Thermo Fisher), following the manufacturer's protocol. Reverse transcription of RNA was carried out using a firststrand cDNA synthesis kit (Invitrogen). The expression levels of genes were measured by qRT-PCR using SYBR Green and an Mx3005P QPCR instrument (Agilent Technologies, USA). The thermal program used as follows: $3 \mathrm{~min}$ at $95^{\circ} \mathrm{C}$ followed by 40 cycles of $15 \mathrm{~s}$ at $95^{\circ} \mathrm{C}$ and $1 \mathrm{~min}$ at $60^{\circ} \mathrm{C}$. mRNA expression relative to GAPDH expression was calculated by the $\Delta \Delta \mathrm{Ct}$ method. The primer sequences used for qRT-PCR analysis are listed in Table 1.

\section{Western Blot Analysis}

Cells were lysed in RIPA lysis buffer containing a protease and phosphatase inhibitor cocktail on ice for $30 \mathrm{~min}$ and then centrifuged at $13,000 \mathrm{~g}$ for $10 \mathrm{~min}$. Protein concentrations were determined using a BCA protein assay kit. Equal amounts $(20 \mu \mathrm{g})$ of protein were separated by $10 \%$ sodium dodecyl sulfate-polyacrylamide gel electrophoresis (SDS-PAGE) and transferred onto a polyvinylidene fluoride membrane. The membranes were blocked with 5\% bovine serum albumin (BSA) and then incubated with diluted primary antibodies in $5 \%$ BSA with TBST at $4{ }^{\circ} \mathrm{C}$ overnight. The membranes were washed three times with TBST and then incubated with a secondary antibody for 1 h. After three washes with TBST, the proteins were visualized using a SuperSignal West Pico Kit and then imaged by a ChemiDoc ${ }^{\mathrm{TM}}$ XRS.

\section{Immunocytochemistry}

Immunocytochemistry was used to investigate HMGB1 immunolocalization. MMC and RAW264.7 cells were seeded in 24-well plates at a density of $5 \times 10^{4}$ cells/well and cultured for $24 \mathrm{~h}$. The cells were pretreated with liposomes for $2 \mathrm{~h}$ and then stimulated with LPS $(1 \mu \mathrm{g} / \mathrm{mL})$ for $24 \mathrm{~h}$. Cells were fixed in $4 \%$ paraformaldehyde for $10 \mathrm{~min}$ and then blocked in 5\% BSA for $1 \mathrm{~h}$, followed by permeabilization in $0.5 \%$ Triton $\mathrm{X}-100$ for $30 \mathrm{~min}$. Then, the cells were incubated with primary antibodies overnight at $4^{\circ} \mathrm{C}$. After washing, Alexa Fluor 488-conjugated anti-rabbit IgG was applied to the cells as the secondary antibody for $1 \mathrm{~h}$ at

Table I Oligomeric Nucleotide Primer Sequence Of Quantitative Reverse Transcriptase Polymerase Chain Reaction

\begin{tabular}{|c|c|c|}
\hline Gene & Forward Primer (5'-3') & Reverse Primer $\left(5^{\prime}-3^{\prime}\right)$ \\
\hline Hmgbl & GCATCCTGGCTTATCCATTGG & GGCTGCTTGTCATCTGCTA \\
\hline T/r4 & AAATGCACTGAGCTTTAGTGGT & TGGCACTCATAATGATGGCAC \\
\hline Myd88 & ATCGCTGTTCTTGAACCCTCG & CTCACGGTCTAACAAGGCCAG \\
\hline Irak4 & CATACGCAACCTTAATGTGGGG & GGAACTGATTGTATCTGTCGTCG \\
\hline$N f-\kappa b p 65$ & GCGTACACATTCTGGGGAGT & CCGAAGCAGGAGCTATCAAC \\
\hline Gapdh & TCAACGGCACAGTCAAGG & ACTCCACGACATACTCAG \\
\hline
\end{tabular}


room temperature. Fluorescence images were obtained under a fluorescence microscope.

\section{Cytokine Assay}

Cytokines in culture supernatants were assayed using commercially available IL-6, IL-8, TNF- $\alpha$, and IL-1 $\beta$ ELISA kits (MultiSciences (Zhejiang, China), in accordance with the manufacturer's instructions.

\section{Statistical Analysis}

Results are presented as means \pm SD. Statistical analysis was performed by ANOVA (GraphPad Prism, V6.02). The two-tailed Student's $t$-test was used to compare two groups. Significant differences between or among groups are indicated by ${ }^{*} \mathrm{p}<0.05,{ }^{* *} \mathrm{p}<0.01$, and ${ }^{* * *} \mathrm{p}<0.001$.

\section{Results}

\section{Synthesis Of DSPE-PEG2000-TAT}

DSPE-PEG2000-TAT was synthesized by conjugating the sulfhydryl groups in Cys-TAT to the Mal of DSPEPEG2000-Mal. The synthetic procedure for DSPEPEG2000-TAT is illustrated in Figure 1A. The 1H-NMR spectra of DSPE-PEG2000-TAT is shown in Figure 1B. The peak at $3.6 \mathrm{ppm}$ was the PEG resonance peak indicating the existence of a hydrophilic PEG long-chain, and the peak of Mal groups was located at $6.72 \mathrm{ppm}$. The Mal peak of DSPE-PEG2000-Mal disappeared in the spectrum, confirming successful conjugation of TAT and DSPE-PEG2000-Mal.

\section{TAT-CLs-DHA/siRNA Preparation And}

\section{Characterization}

The DHA loaded into cationic liposome was prepared by a thin film hydration technique, and then HMGB1 siRNA was bound to the surface of positively charged liposomes via electrostatic interactions to form TAT-CLs-DHA/ siRNA. The average particle sizes of CLs-DHA and TAT-CLs-DHA were 116.2 and $124.2 \mathrm{~nm}$ with narrow polydispersity indexes (PDIs) of 0.171 and 0.185 , respectively (Table 2). The zeta potential of CLs-DHA and TATCLs-DHA were 52.6 and $56.5 \mathrm{mV}$, respectively (Table 2). These results suggested that the modification by TAT increased the particle size and zeta potential of liposomes because of the positive charge of TAT.

The particle sizes of CLs-DHA/siRNA and TAT-CLsDHA/siRNA were 140.3 and $144 \mathrm{~nm}$, respectively, and their zeta potentials were 27.3 and $35.8 \mathrm{mV}$ respectively (Table 2, Figure 2A and B). These results suggested that
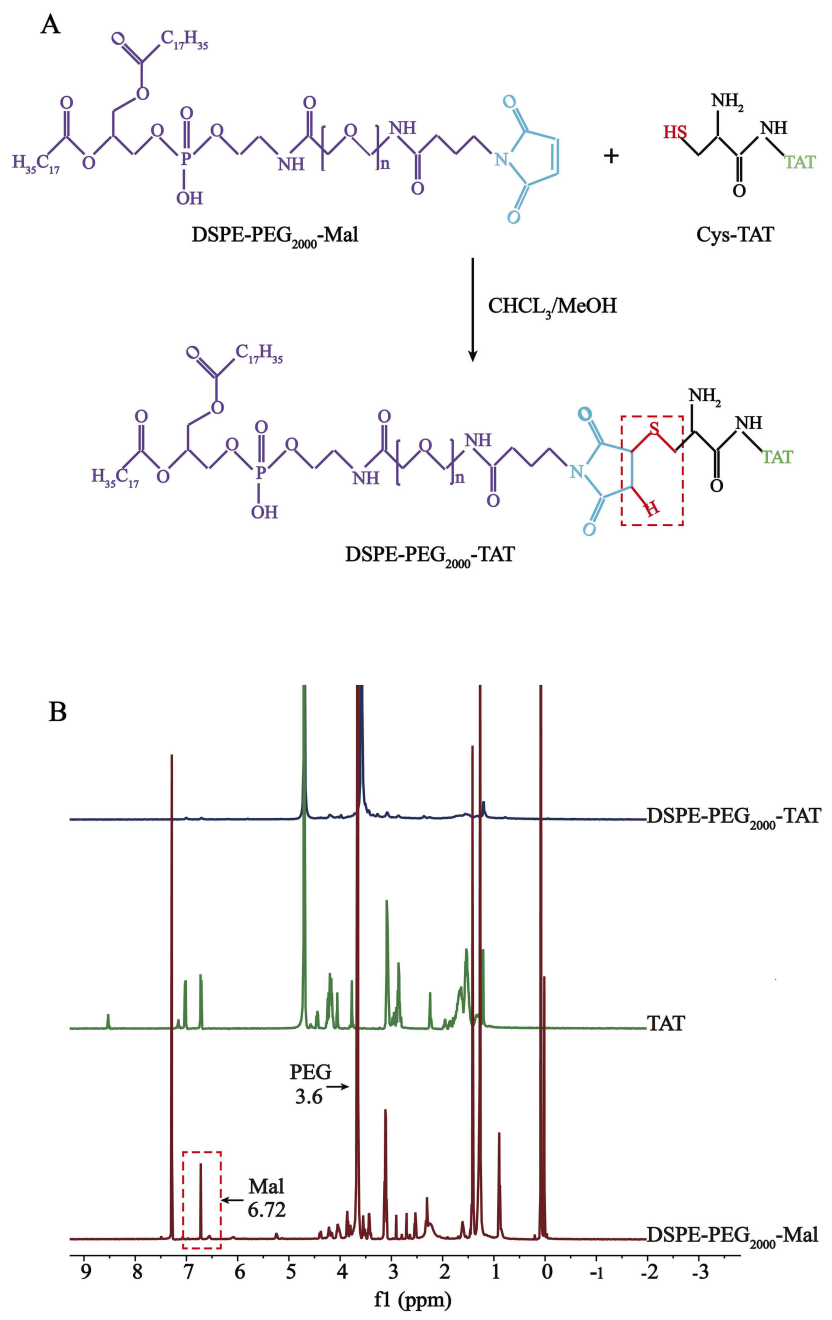

Figure I Synthesis of DSPE-PEG2000-TAT. (A) Synthetic route of DSPE-PEG2000TAT. (B) IH-NMR spectra of TAT, DSPE-PEG2000-Mal and DSPE-PEG2000-TAT.

siRNA binding to cationic liposomes increased the particle size and decreased the zeta potential because of the negative charge of siRNA. The EE\% of DHA in CLs-DHA, TAT-CLsDHA, CLs-DHA/siRNA, and TAT-CLs-DHA/siRNA was 87.2, 84.4, 87.3, and $85.3 \%$ respectively (Table 2 ).

When cationic liposomes encapsulated siRNA at an increasing DOTAP:siRNA ratio, the particle size of liposomes was decreased and their zeta potential was increased because of the cation (Figure 2C).

We mixed the liposomes and HMGB1 siRNA at ratios of 5:1, 10:1, 15:1, 20:1, 25:1, 30:1, and 40:1 (DOTAP: siRNA, $\mathrm{w} / \mathrm{w})$ and performed agarose gel electrophoresis to investigate the optimal ratio. When cationic liposomes and siRNA were mixed at a ratio of 10:1 (DOTAP:siRNA, w/w), the siRNA was fully entrapped in the loading wells with liposomes, indicating that siRNA was fully loaded into liposomes at a ratio of 10:1 (Figure 2F). 
Table 2 Key Parameters Of CLs-DHA, CLs-DHA/siRNA, TAT-CLs-DHA And TAT-CLs-DHA/siRNA Liposomes. Data Are Expressed As Mean $\pm \operatorname{SD}(n=4)$

\begin{tabular}{|l|l|l|l|l|}
\hline Liposome & Particle Size (nm) & PDI & Zeta Potential (mv) & DHA Entrapment (\%) \\
\hline CLs-DHA & $116.2 \pm 3.9$ & $0.171 \pm 0.006$ & $52.6 \pm 3.25$ & $87.2 \% \pm 2.74$ \\
CLs-DHA/siRNA & $140.3 \pm 2.6$ & $0.194 \pm 0.011$ & $27.3 \pm 4.52$ & $87.3 \% \pm 3.57$ \\
TAT-CLs-DHA & $124.2 \pm 1.2$ & $0.185 \pm 0.004$ & $56.5 \pm 3.69$ & $84.4 \% \pm 2.50$ \\
TAT-CLs-DHA/siRNA & $144 \pm 3.8$ & $0.213 \pm 0.005$ & $35.8 \pm 3.07$ & $85.3 \% \pm 2.13$ \\
\hline
\end{tabular}

Figure 2D shows that there was no significant change in particle size or PDI for TAT-CLs-DHA/siRNA in 50\% serum at up to $72 \mathrm{~h}$ of incubation, suggesting its excellent stability. We also detected the serum stability of siRNA encapsulated in liposomes. The results showed that the siRNA in liposomes was completely degraded after $48 \mathrm{~h}$. These results suggested that siRNA in cationic liposomes was protected in serum for up to $36 \mathrm{~h}$, but some siRNA was possibly degraded by adhesion to the liposome surface (Figure 2G).

The surface morphology of TAT-CLs-DHA/siRNA was determined by TEM (Figure 2E). the results showed a spherical shape and smooth surface. The particle size measured by TEM was consistent with the results of the DLS method.

\section{Cell Viability}

The cytotoxic effects of various concentrations of TAT-CLs according to the content of DOTAP in liposomes were evaluated in MMC, RAW264.7, and HEK 293 cells. When the concentrations of TAT-CLs according to the content of DOTAP were less than $300 \mu \mathrm{g} / \mathrm{mL}$, no significant decrease in viability was observed in the cells. When the concentrations exceeded $300 \mu \mathrm{g} / \mathrm{mL}$, cell viability was diminished. After $24 \mathrm{~h}$ of TAT-CL $(750 \mu \mathrm{g} / \mathrm{mL})$ treatment, 32\% of HEK 293 cells $28 \%$ of MMC cells, and $40 \%$ of RAW264.7 cells had undergone cell death. After $24 \mathrm{~h}$ of TAT-CL $(1500 \mu \mathrm{g} / \mathrm{mL})$ treatment, as expected, $54 \%$ of HEK 293 cells, $70 \%$ of MMC cells, and $62 \%$ of RAW264.7 cells had undergone cell death (Figure 3). These results showed that the TAT-modified cationic liposome carrier exhibited low cytotoxicity when the DOTAP concentration was $<300 \mu \mathrm{g} / \mathrm{mL}$. Therefore, we chose an appropriate concentration of TAT-CLs $(<300 \mu \mathrm{g} /$ $\mathrm{mL}$ ) for subsequent experiments.

\section{Cellular Uptake}

Intracellular kinetics of the Cy3-siRNA/liposomes were monitored by confocal laser scanning microscopy (CLSM) and flow cytometry (FCM) in MMC cells. As shown in Figure 4A, the red fluorescence of Cy3-siRNA increased constantly from 0 to $4 \mathrm{~h}$, and the fluorescence intensity reached its maximum at $4 \mathrm{~h}$. These results showed that Cy3-siRNA delivered by TAT-CLs-DHA was noticeably taken up by MMC cells. Based on the quantitative analysis by flow cytometry, the signal was gradually increased within $4 \mathrm{~h}$ (Figure 4B). Figure 4C also shows that TAT-CLs-DHA/siRNA delivered the siRNA into cells more efficiently than CLs-DHA/siRNA.

Cy3-siRNA was used to prepare fluorescently labeled Cy3- siRNA/liposomes, as shown in (Figure 5A). The TAT-CLs-DHA/siRNA showed remarkably enhanced cellular uptake by Cy3-siRNA by RAW264.7, and MMC cells, displaying significant increases compared with the unmodified CLs-DHA/siRNA. These results were consistent with FCM analysis (Figure $5 \mathrm{~B}$ and $\mathrm{C}$ ). This suggests that TAT-CLs-DHA/siRNA deliver siRNA into cells more efficiently than CLs-DHA/siRNA.

\section{TAT-CLs-DHA/siRNA Inhibit LPS-Induced MMC Cell Proliferation}

We first used various concentrations of LPS to stimulate MMC cell proliferation. The MTT assay results showed that the various concentrations of LPS stimulated MMC cell proliferation to various degrees, among which the effect of $7 \mu \mathrm{g} / \mathrm{mL}$ LPS was the most evident. When the concentration of LPS was increased to $10 \mu \mathrm{g} / \mathrm{mL}$, cell proliferation was partially inhibited by LPS toxicity (Figure 6A). These results indicated that a certain degree of inflammation stimulated MMC cell growth. Therefore, $7 \mu \mathrm{g} / \mathrm{mL}$ LPS was selected as the stimulation dose for subsequent experiments.

Inhibition of cell proliferation by various concentrations of DHA, Cls-DHA, Cls-DHA/siRNA, and TAT-CLs-DHA/ siRNA was assessed by MTT assays. We observed that DHA concentrations of $0.001-0.1 \mu \mathrm{g} / \mathrm{mL}$ and siRNA concentrations of $0.005-0.5 \mathrm{nM}$ in liposomes exerted no significant inhibitory effect on cell proliferation, and treatment 
A

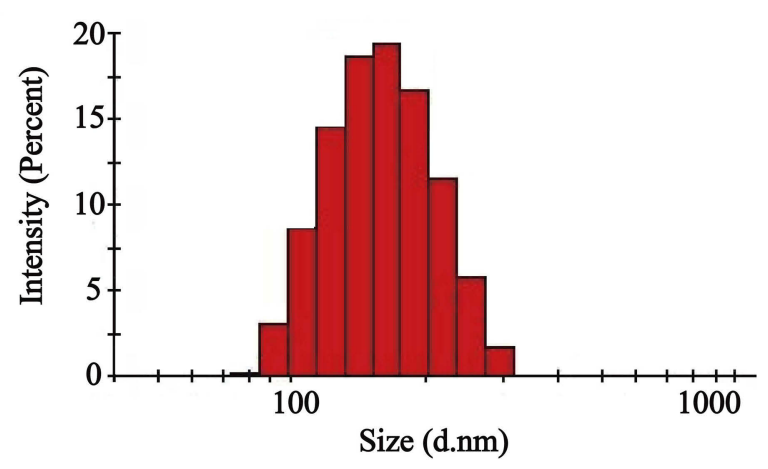

C

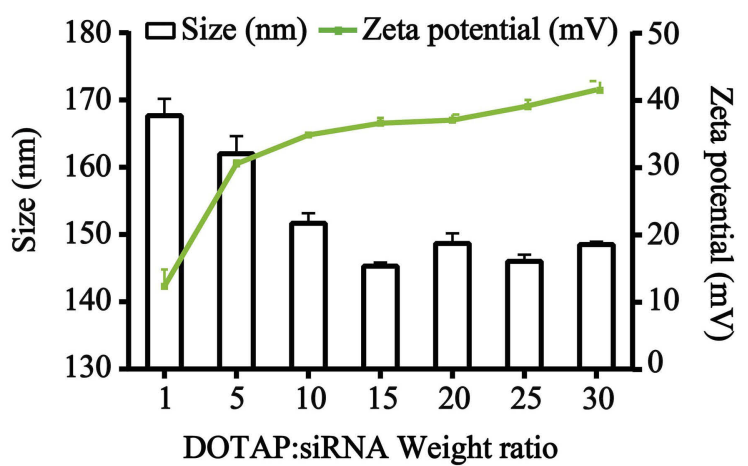

B

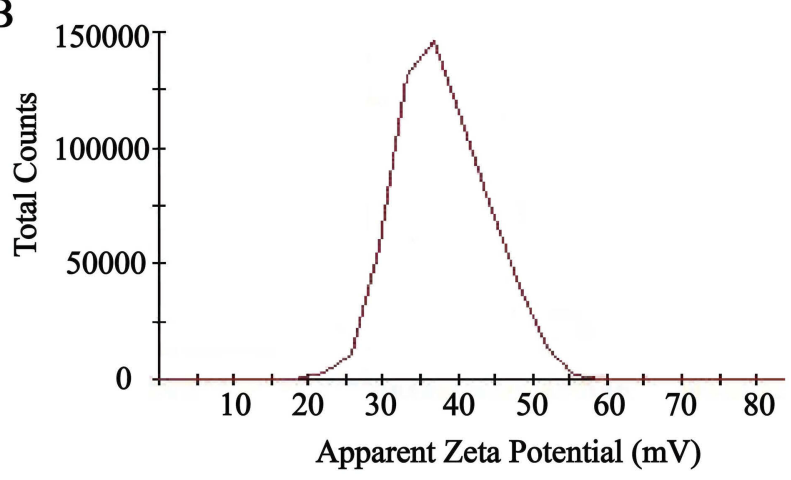

D

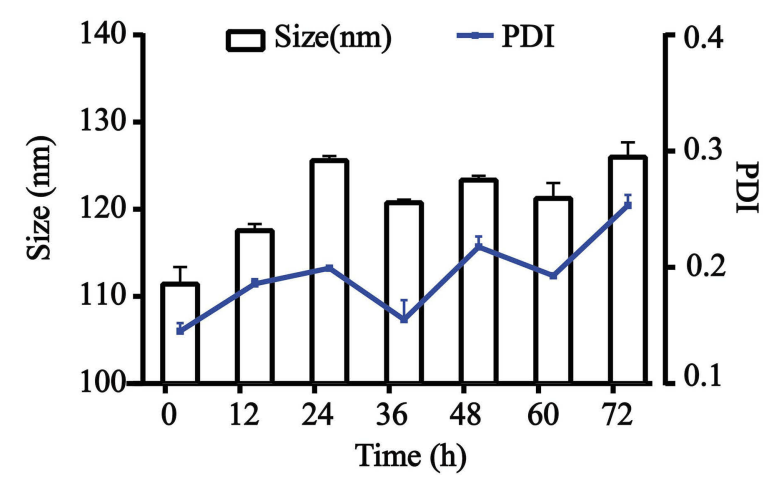

E

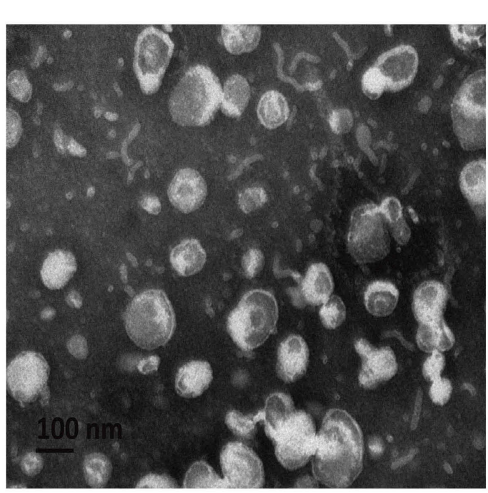

F

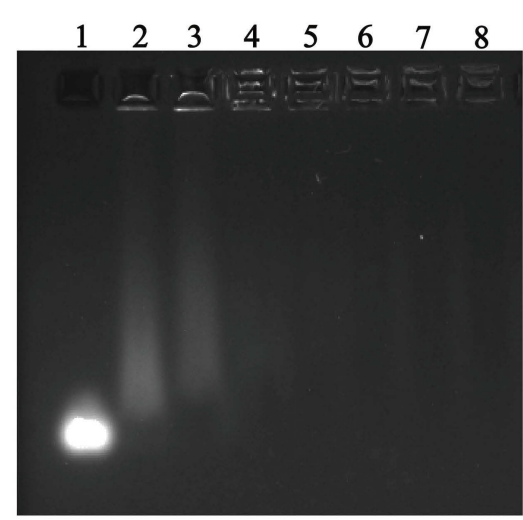

G

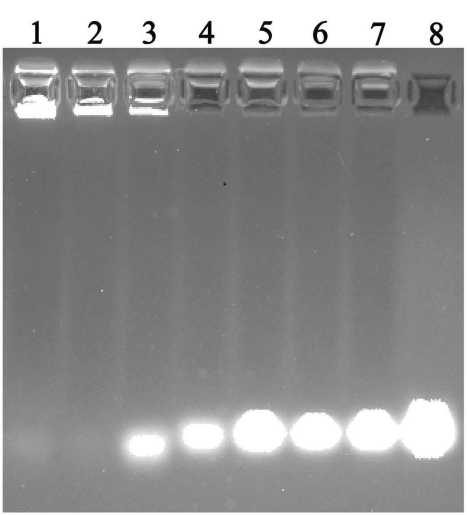

Figure 2 Characterization of the TAT-CLs-DHA/siRNA nanocomplexes. (A) Particle size distribution. (B) Zeta potential. (C) Size distribution and zeta potential of the TATCLs-DHA/siRNA at different DOTAP:siRNA ratios. (D) Particle size stability of TAT-CLs-DHA/siRNA in serum within 72h. (E) TEM image. (F) The agarose gel electrophoresis image illustrating siRNA loading efficiency at the following weight ratio of DOTAP:siRNA (w/w): 0:I (siRNA only, control), 5:I, I0:I, I5:I, 20:I, 25:I, 30:I, 40:I (lanes I-8, respectively). (G) siRNA serum stability: 60h, 48h, 36h, 24h, 12h, 6h, 3h, siRNA only (lanes I-8, respectively). Data represent mean \pm SD (n $=4$ ).

of the cationic liposomes with the DHA concentrations of $0.5-20 \mu \mathrm{g} / \mathrm{mL}$ )and siRNA concentrations of $2.5-100 \mathrm{nM}$ exerted a significant inhibitory effect. This finding indicated that the effect of DHA on LPS-induced MMC cell proliferation was dose dependent. The cell proliferation rates were significantly decreased in the TAT-CL-DHA/siRNA group and the order of the inhibitory effect was TAT-CLsDHA/siRNA > CLs-DHA/siRNA > CLs-DHA > DHA. This result indicates that DHA and HMBG1 siRNA have synergistic effects on LPS-induced MMC cell proliferation (Figure 6B).

To explore the relationship between HMGB1 gene expression and MMC cell proliferation, we first used TAT-CLs to transfect siRNA into cells and examine its ability to downregulate the HMGB1 gene. Western blot results indicated that the siRNA downregulated the HMGB1 gene (Figure 6C). Quantitative RT-PCR showed similar results (Figure 6E). Next, we investigated 


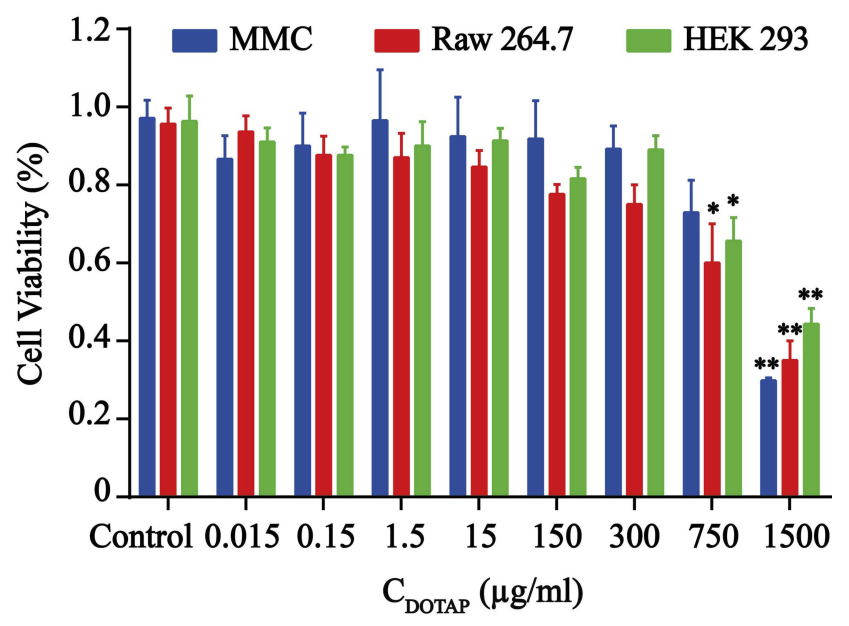

Figure 3 Cytotoxic effect of TAT-CLs in MMC, RAW264.7 and HEK-BlueTMhTLR4 cells. Cells were treated with blank cationic liposomes. Data represent mean $\pm S D(n>5) .{ }^{* *} p<0.01$ and $*_{p}<0.05$ compared to control group.

expression of the HMGB1 gene in the inflammatory state and the inhibition of gene expression by liposomes. LPS was used to stimulate MMC cells, followed by treatment with liposomes. We found increased expression of the HMGB1 gene after LPS Treatment. Expression was inhibited by TAT-CLs-DHA/siRNA and the effect was better than that exerted by CLs-DHA/siRNA after $48 \mathrm{~h}$ of treatment. Quantitative RT-PCR showed similar results to Western blotting in MMC cells (Figure 6D and F).

Immunocytochemistry was used to investigate immunolocalization of HMGB1. In agreement with Western blot results, immunofluorescence indicated that LPS increased expression of HMGB1. Translocation of HMGB1 from the nucleus to the cytoplasm occurred when the cells received an inflammatory (LPS) stimulus. However, when MMC cells were stimulated by LPS and treated with TAT-CLsDHA/siRNA, we clearly observed a decrease of HMGB1 in the cytoplasm and retention in the nuclei of cells (Figure 7).

\section{TAT-CLs-DHA/siRNA Inhibit LPS-Induced TLR4 Activation}

Toll-like receptor 4 activation is a hallmark of inflammation, and HEK-BlueTM-hTLR4 cells stably overexpress TLR4. Therefore, we chose HEK-BlueTM-hTLR4 cells to investigate the specific effect of TAT-CLs-DHA/ siRNA on TLR4 activity following LPS stimulation. The results showed that $\mathrm{NF}-\mathrm{\kappa B}$ activity reached a maximum at $1 \mu \mathrm{g} / \mathrm{mL}$ LPS and did not increase when the LPS concentration exceeded $1 \mu \mathrm{g} / \mathrm{mL}$ (Figure 8A). Therefore, we chose $1 \mu \mathrm{g} / \mathrm{mL}$ LPS as the stimulation dose for subsequent experiments.

HEK-BlueTM-hTLR4 cells were treated with $1 \mu \mathrm{g} / \mathrm{mL}$ LPS along with various concentrations of DHA, CLssiRNA, Cls-DHA, Cls-DHA/siRNA, and TAT-CLs-DHA/ siRNA according to the content of DHA. All groups had inhibited TLR4 activation in a concentration-dependent manner. The order of the effect was TAT-CLs-DHA/ siRNA > CLs-DHA/siRNA > CLs-DHA > DHA, indicating good synergy between DHA and HMGB1 siRNA to inhibit TLR4 activity (Figure 8B).

\section{Effect Of TAT-CLs-DHA/siRNA On} Protein Expression Levels Of The TLR4/ NF-кB Signaling Pathway

The above results indicated TAT-CLs-DHA/siRNA inhibited LPS-induced TLR4/NF-кB activation. To explore the mechanism of TAT-CLs-DHA/siRNA, we measured the protein expression levels of HMGB1, TLR4, MyD88, IRAK4, and NF-кB of LPS (1 $\mu \mathrm{g} / \mathrm{mL})$-stimulated RAW264.7 cells after the various treatment. As shown in Figure $8 \mathrm{C}$, LPS induced stronger protein expression of HMGB1, TLR4, MyD88, IRAK4, and NF-кB compared with the control group. After treatment with DHA, CLssiRNA, Cls-DHA, Cls-DHA/siRNA, and TAT-CLs-DHA/ siRNA for $24 \mathrm{~h}$, the expression of all proteins was decreased significantly. Importantly, TAT-CLs-DHA/ siRNA had the most obvious inhibitory effect. Quantitative analysis clearly demonstrated the reduction in protein expression (Figure 8D-H)

These results were confirmed by qRT-PCR. mRNA expression levels of TLR4, NF-кB, IRAK4, MyD88, and HMGB1 was increased in LPS-induced RAW264.7 cells, especially MyD88 and IRAK4 mRNA levels, and the mRNA expression levels of each group was significantly downregulated after treatment with TAT-CLs-DHA/siRNA showing optimal downregulation. These results were consistent with Western blot results (Figure 9).

Immunofluorescence was used to observe the expression of HMGB1 in LPS-activated RAW264.7 cells. The results showed that HMGB1 was overexpressed and some of the protein had translocated from the nucleus to the cytoplasm. When the cells treated with TAT-CLs-DHA/ siRNA, we clearly observed a decrease in HMGB1 expression and retention of HMGB1 in the nuclei of cells (Figure 10). 
A
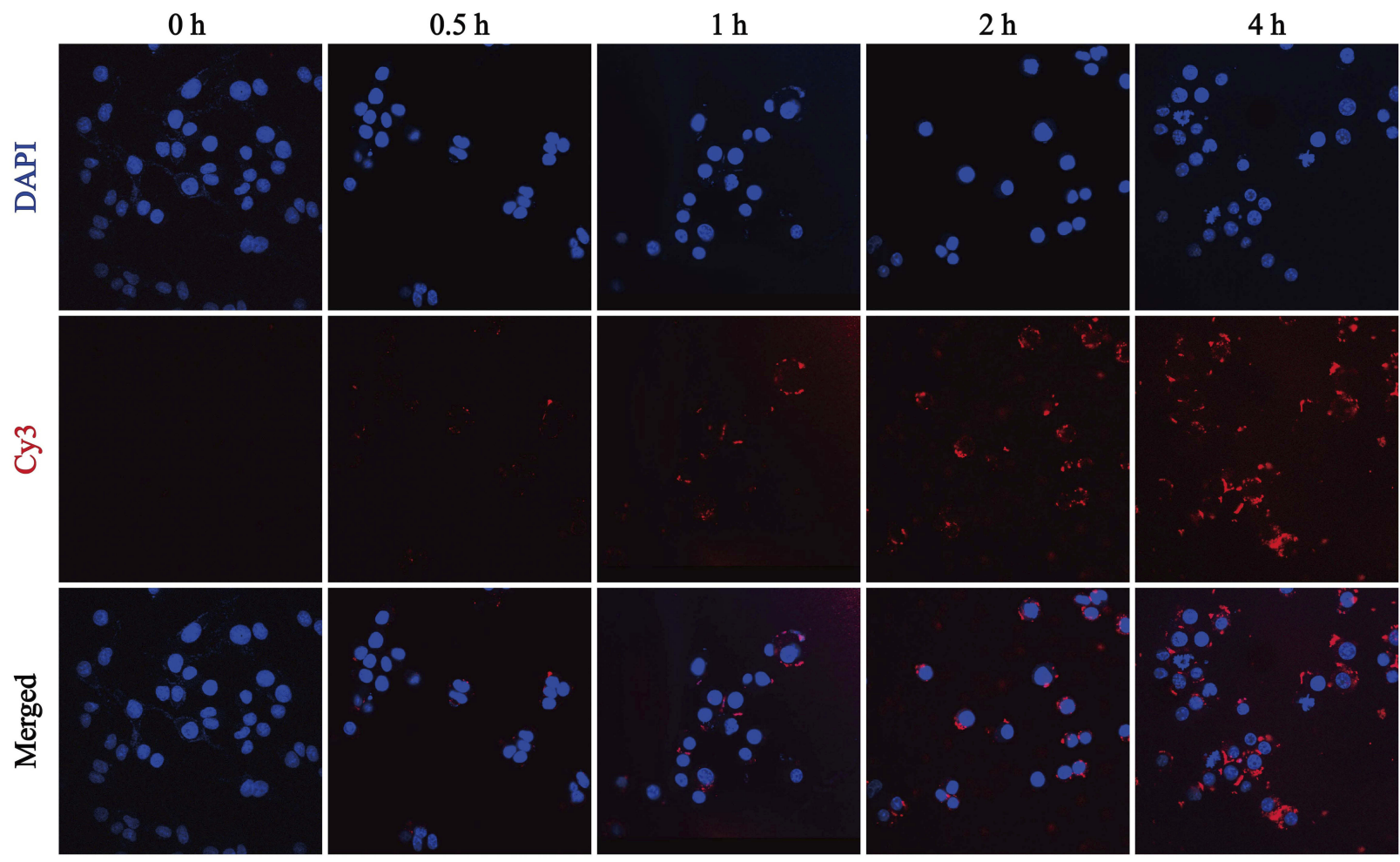

B

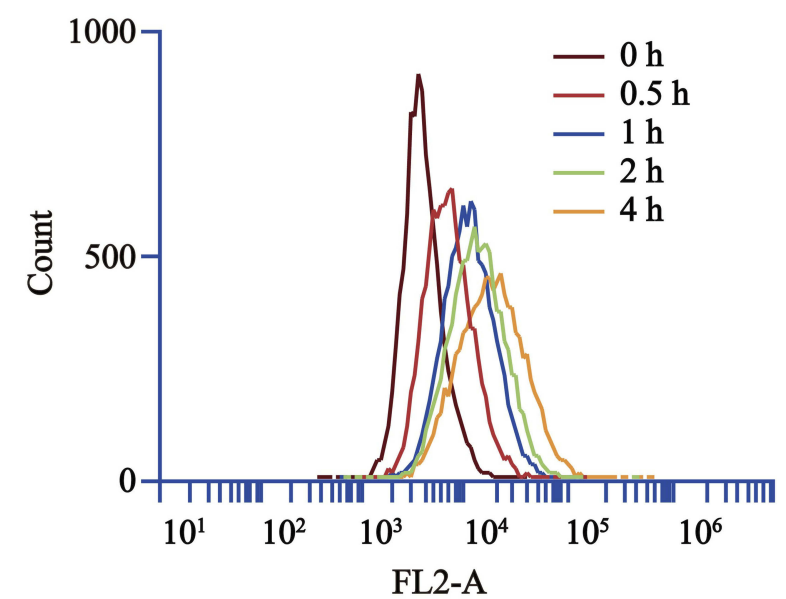

C

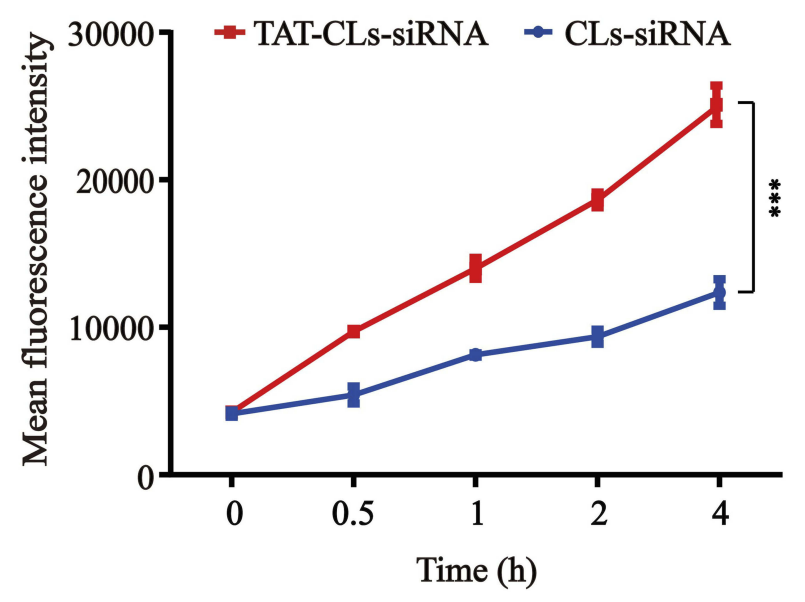

Figure 4 Uptake kinetics of TAT-CLs-DHA/Cy3-siRNA liposomes in MMC cells. (A) Intracellular localization by CLSM. (B) Flow cytometry quantitative analysis of the uptake process. (C) Mean fluorescence intensity of TAT-CLs-DHA/Cy3-siRNA and CLs-DHA/Cy3-siRNA. Data represent mean \pm SD (n $>5$ ). $* * * p<0.00$ I.

Effect Of TAT-CLs-DHA/siRNA On The Production Of Proinflammatory

\section{Cytokines}

We further explored cytokines (TNF- $\alpha$, IL-6, IL-8, and IL$1 \beta)$ released by LPS (1 $\mu \mathrm{g} / \mathrm{mL})$-stimulated RAW264.7 after treatment with liposomes containing the control, LPS, DHA, CLs-siRNA, Cls-DHA, Cls-DHA/siRNA, and TAT-CLs-DHA/siRNA. After LPS stimulation, we observed abundant release of inflammatory factors by RAW264.7 cells. Conversely, these cytokines were decreased after the various treatments. We found that TAT-CLs-DHA/siRNA led to a robust decrease in the levels of multiple cytokines in LPS-induced RAW264.7 cells compared with the other groups (Figure 11). 
A
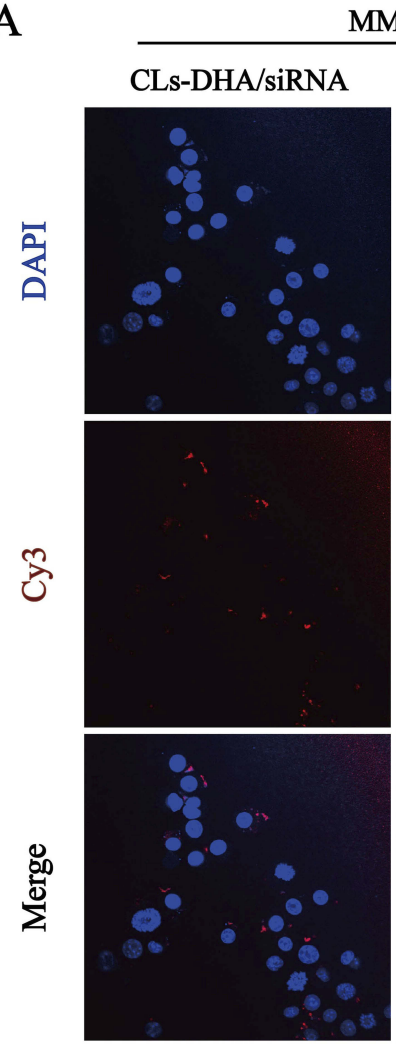

B

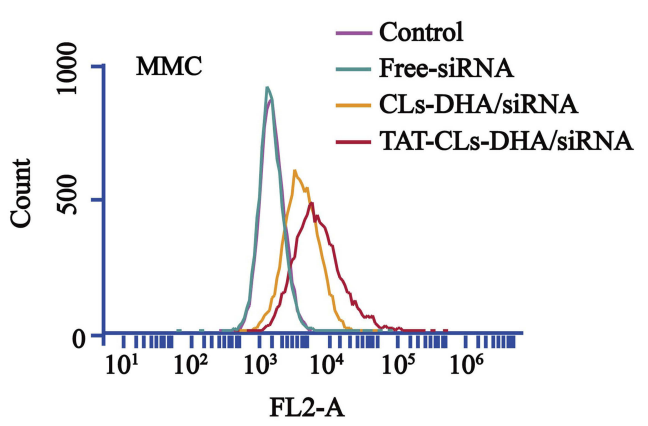

C
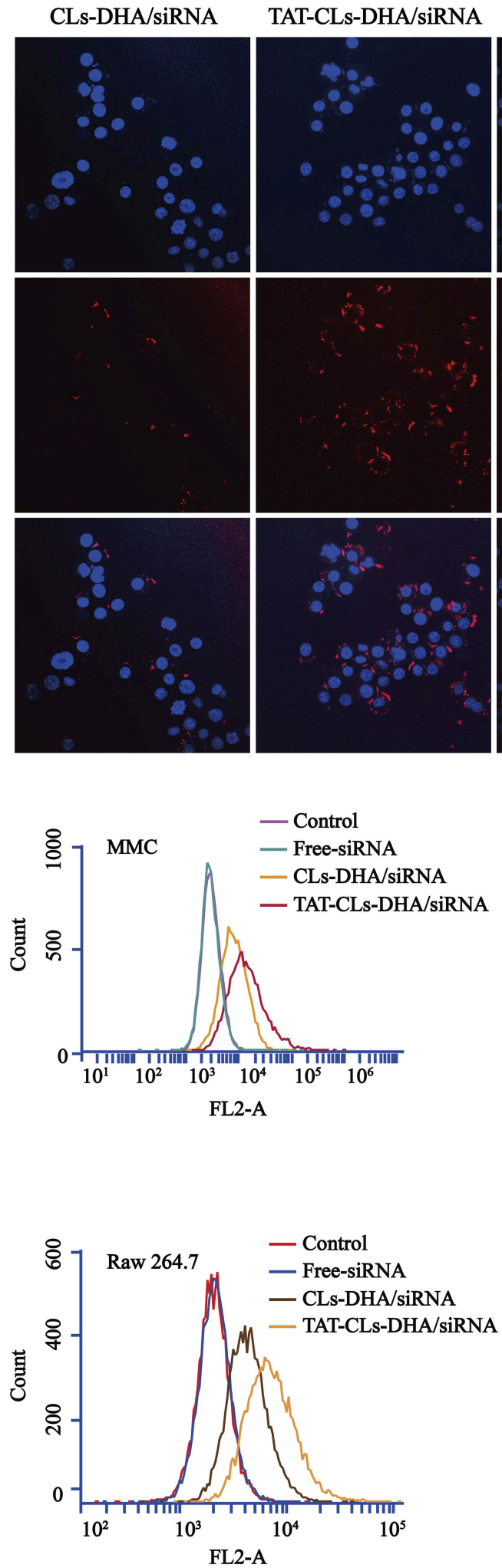

Raw264.7

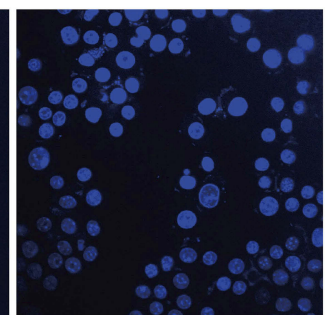

TAT-CLs-DHA/siRNA
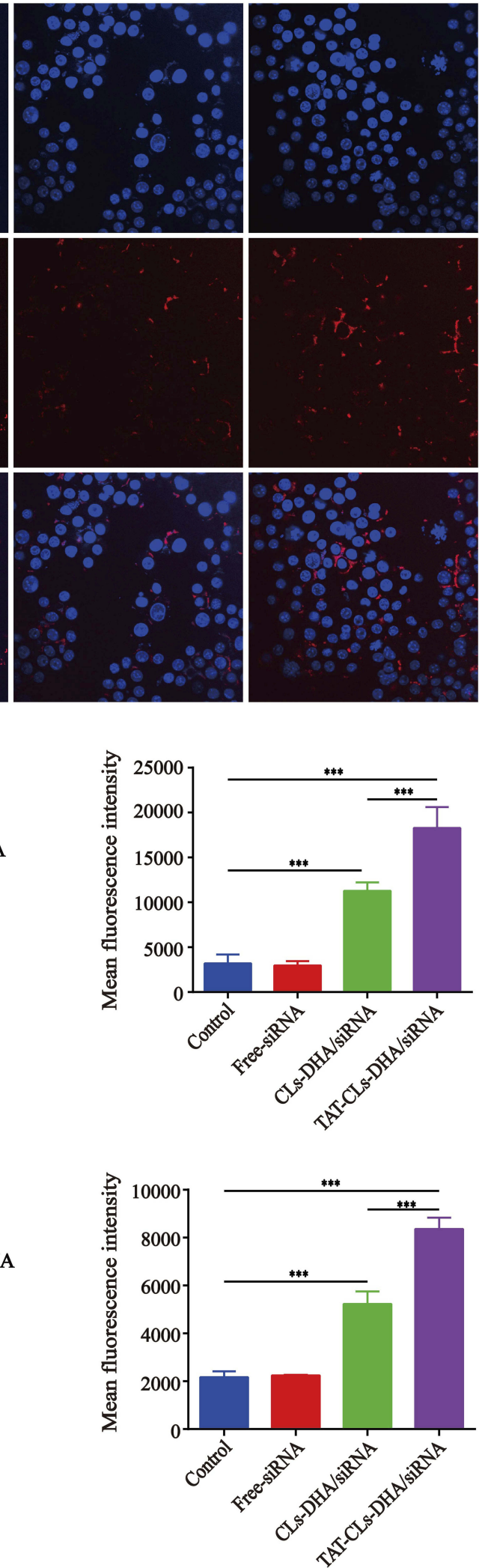

Figure 5 In vitro cellular uptake of different formulations, including TAT-CLs-DHA/Cy3-siRNA and CLs-DHA/Cy3-siRNA liposomes, conducted in MMC cell and RAW264.7 cells for $4 \mathrm{~h}$. The concentration of Cy3 was 100nM. (A) Intracellular localization by CLSM. (B, C) Typical flow cytometry profiles. Data represent mean \pm SD ( $>5$ ). *** $\mathrm{P}<0.00 \mathrm{I}$. 
A

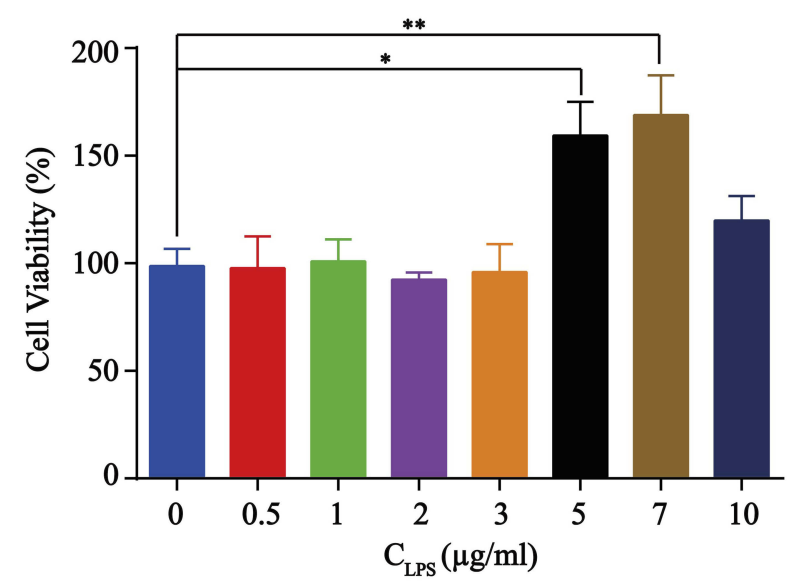

C

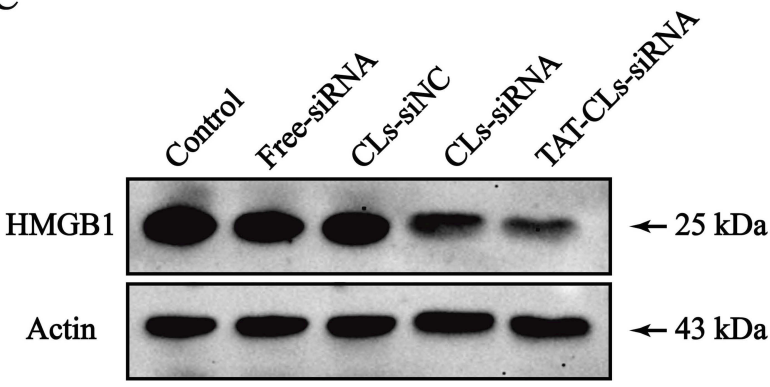

B

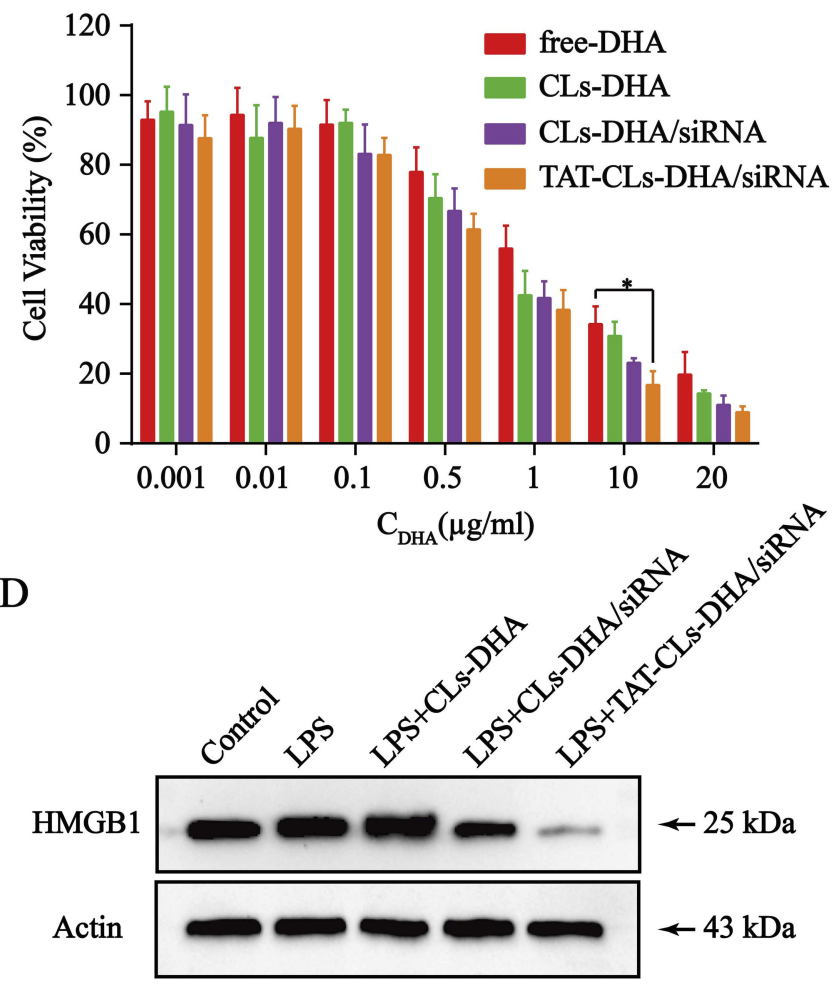

$\mathrm{F}$

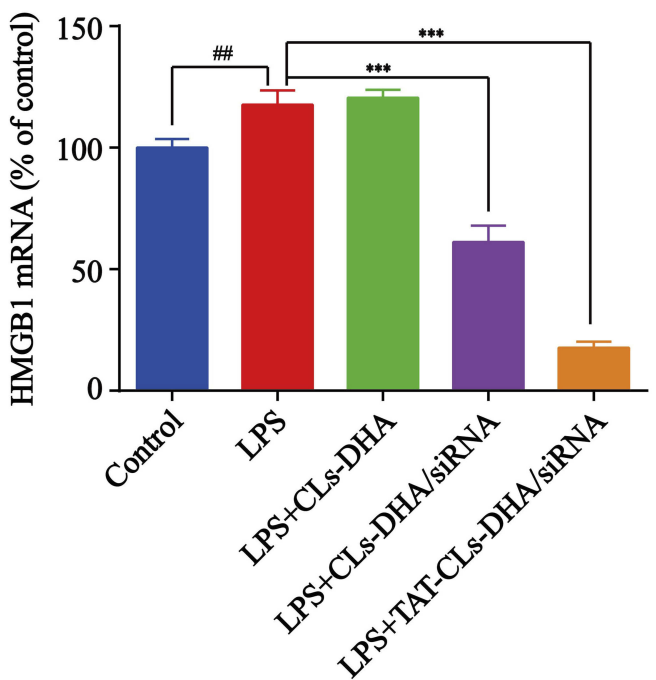

Figure 6 The effects of different formulations, including DHA, CLs-DHA, CLs-DHA/siRNA and TAT-CLs-DHA/siRNA liposomes on MMC cells proliferation following LPS treatment. (A) Different concentrations of LPS stimulate the proliferation of MMC cells. (B) Liposomes inhibit LPS-induced MMC cell proliferation analyzed by MTT assay. (C) Western blotting of HMGBI expression in the MMC cells after treated with HMGBI siRNA liposomes. (D) Effects of different formulations on LPS-induced HMGBI expression in MMC cells detected by Western blot. (E) qRT-PCR quantitative analysis of the expression of HMGBI in mRNA level after treated with HMGBI siRNA liposomes. (F) qRT-PCR quantitative analysis of the expression of HMGBI in mRNA level after treated with different formulations. Data represent mean \pm SD ( $\mathrm{n}>5$ ). $* * * \mathrm{p}<$ 0.001 , ** $\mathrm{p}<0.01$ and ${ }^{*} \mathrm{p}<0.05$. ${ }^{\# *}<0.01$ compared to control group.

\section{Discussion}

Systemic lupus erythematosus (SLE) is a multisystem autoimmune disease. Studies have shown that the Tolllike receptor pathway is closely related to the occurrence and development of $\mathrm{LN},{ }^{20}$ specifically excessive activation of the TLR4 signaling pathway. ${ }^{21-23}$ Zhang et al revealed that NEAT1 IncRNA contributes to the pathogenesis of lupus and indicated that potentially novel therapeutic 


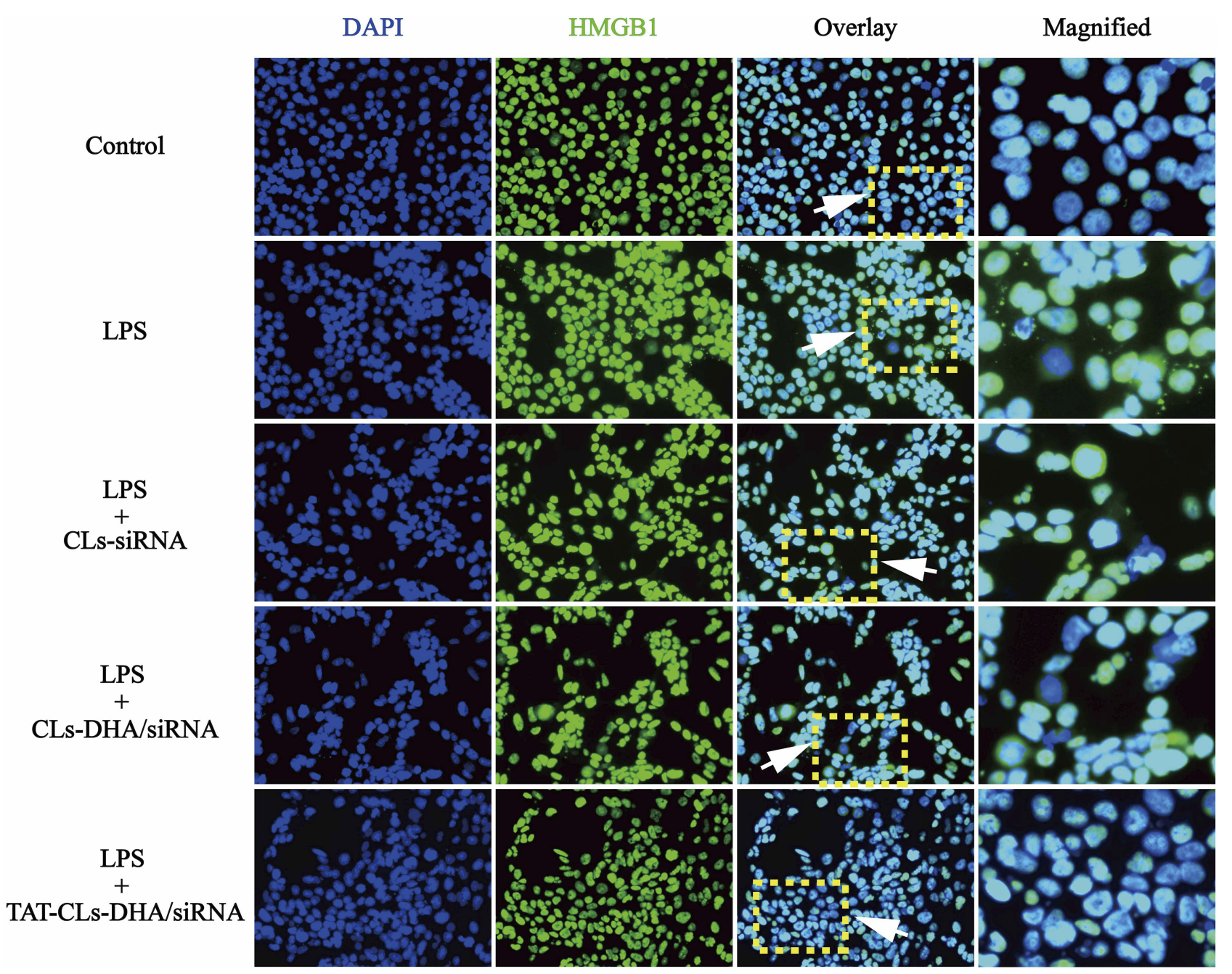

Figure 7 Different formulations, including CLs-siRNA, CLs-DHA/siRNA and TAT-CLs-DHA/siRNA liposomes inhibits LPS-induced HMGBI translocation from nucleus to cytoplasm in MMC cells. Intracellular HMGBI was visualized with green immunofluorescent FITC-staining.

targets are the TLR4-mediated inflammatory process and downstream MAPK signaling pathway. ${ }^{24}$ Lee et al generated transgenic mice with monoclonal anti-dsDNA to investigate the development of lupus. They revealed that anti-dsDNA and bacterial infections have pivotal roles in the pathogenesis of SLE, and inhibition of TLR4 may be therapeutic. ${ }^{25}$ These studies support that TLR4 is a target for the treatment of lupus.

HMGB1 is a DNA-binding protein with a possible role as an inflammatory trigger in autoimmune rheumatic diseases such as SLE. ${ }^{26}$ Ethyl pyruvate improves lupus symptoms by regulating the HMGB1-TLR4 pathway, thereby alleviating the inflammatory microenvironment and delaying the aging of bone marrow mesenchymal stem cells. ${ }^{27}$ TLR4 is a necessary receptor in the proinflammatory process of HMGB1, and NF-KB is downstream of the TLR4 signaling pathway. ${ }^{28}$
Therefore, the HMGB1/TLR4/NF- $\mathrm{kB}$ signaling axis is an important part of the immune regulation process. Currently, the efficacy of drug therapy for LN is unsatisfactory. Some studies have shown that multi-targeted therapy is effective for LN. ${ }^{3}$ Studies suggest that the mechanism of immunosuppression of artemisinin and its derivatives is mediated through the TLR signaling pathway, and this signaling pathway may be a new therapeutic target for lupus erythematosus. ${ }^{7}$ It has been shown that DHA improves MRL/lpr mouse symptoms by inhibiting the TLR4 signaling pathway and producing type 1 interferon. ${ }^{29}$

We generated TAT-modified PEGylated cationic liposomes for siRNA and DHA delivery. In this study, we used liposome formulations containing DOTAP and cholesterol. They have a good drug-loading capacity and siRNA adsorption, which have been well developed and used in many 


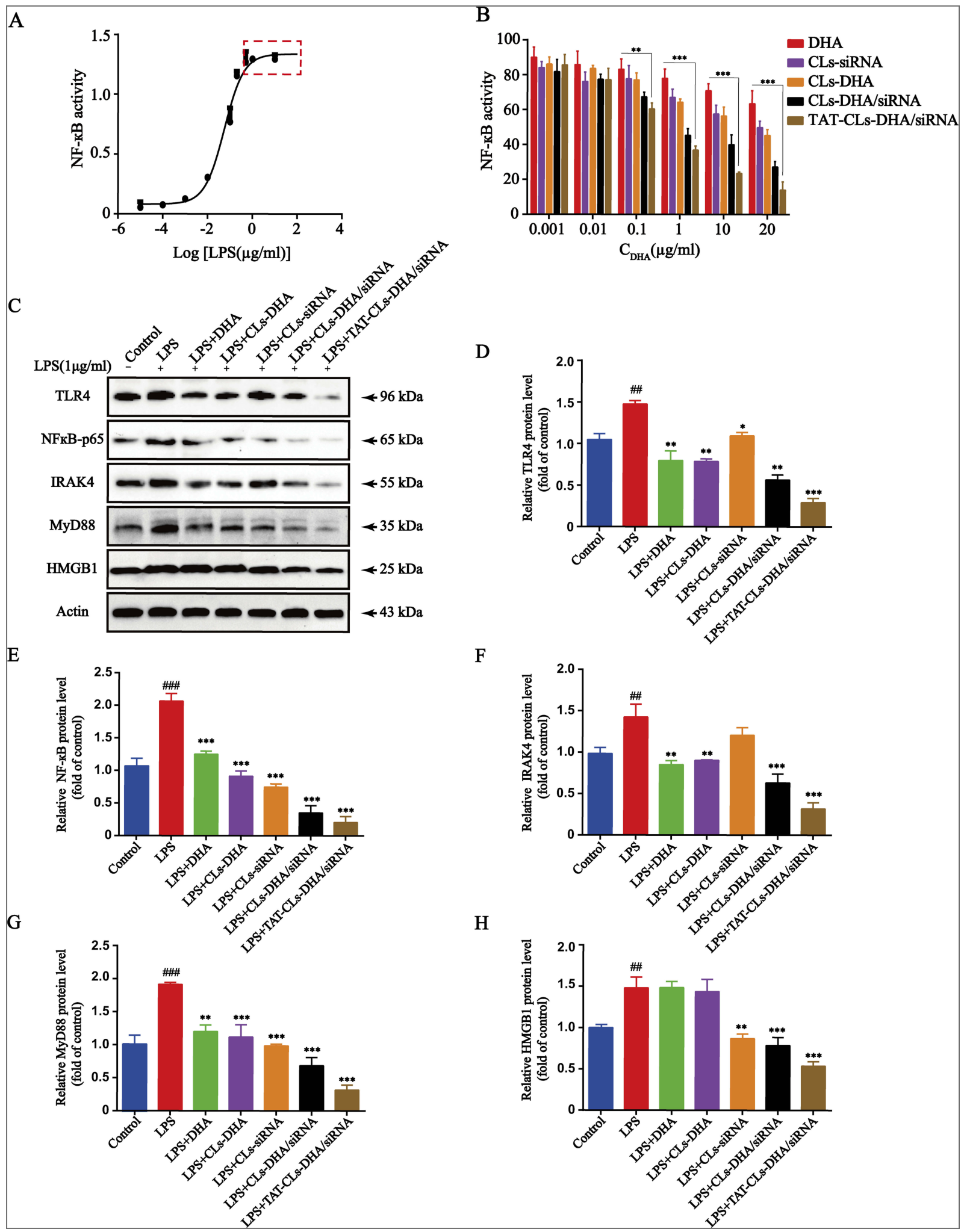

Figure 8 Effects of different formulations, including DHA, CLs-siRNA, CLs-DHA, CLs-DHA/siRNA and TAT-CLs-DHA/siRNA liposomes on LPS-induced TLR4 signalling. (A) Different concentrations of LPS activate TLR4 signaling pathway in HEK-BlueTM-hTLR4 cells. (B) Liposomes inhibite LPS-induced TLR4 activation in HEK-BlueTM-hTLR4 cells. (C) TLR4, NF-KB p65, IRAK4, MyD88 and HMGBI protein expression in RAW264.7 cells detected by Western blot. Quantitative analysis of Western blotting bands including (D) TLR4,

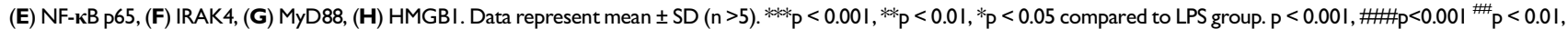
compared to control group. 


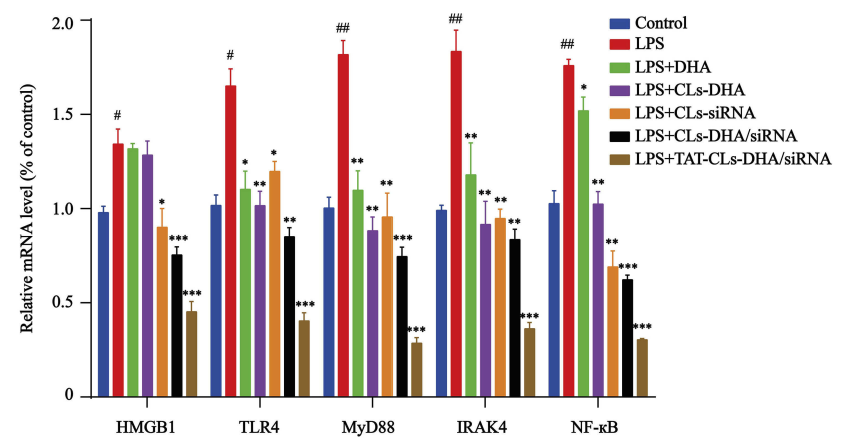

Figure 9 qRT-PCR quantitative analysis of the expression of HMGBI, TLR4, MyD88, IRAK4 and NF-KB in RAW264.7 cells in mRNA level. Data represent mean \pm SD $(n>5)$. *** $p<0.001$, **p $<0.01$, * $p<0.05$ compared to LPS group. $\#^{\#} \mathrm{p}<0.01,{ }^{\#} \mathrm{p}<0.05$ compared to control group.

studies. $^{30,31}$ To further improve the uptake efficiency, a "functional molecule", TAT peptide, was conjugated on the surface of cationic liposomes. The TAT peptide promotes binding between cationic liposomes and cells, thereby enhancing cellular uptake. TAT peptide is one of the most frequently used cell-penetrating peptides (CPPs) and a powerful internalization moiety that has been widely used in the modification of drug delivery systems. ${ }^{32,33}$ Therefore, we designed a TAT-modified cationic liposomal formulation for co-delivery ofHMGB1 siRNA and DHA, two drugs that act simultaneously on different targets of the TLR4 signaling axis with a synergistic effect on LN (Scheme 1).

Our cationic liposome characterizations showed that the average particle size and zeta potential of TAT-CLsDHA/siRNA were around $140 \mathrm{~nm}$ and $35.8 \mathrm{mV}$, respectively. The liposomes had good encapsulation ability for DHA and siRNA, and superior serum stability, which can be applied to potentially increase the feasibility of siRNA therapy in clinical application.
DAPI

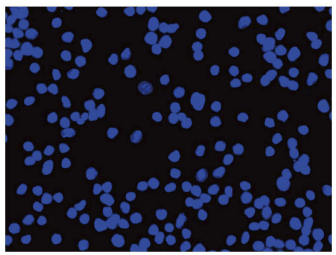

LPS

Control

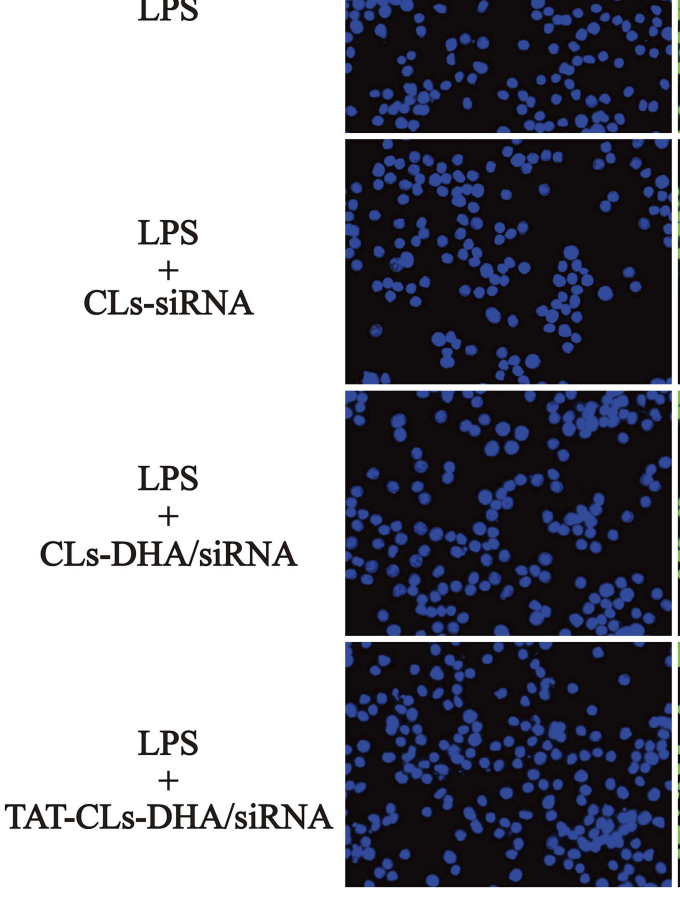

HMGB1

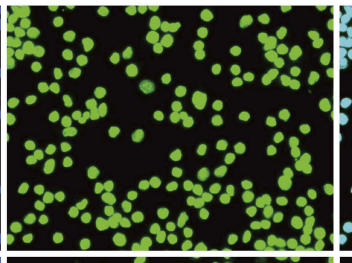

Overlay

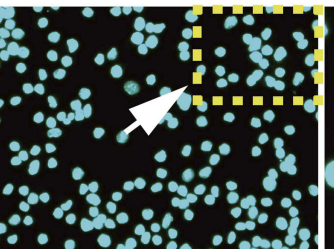

Magnified
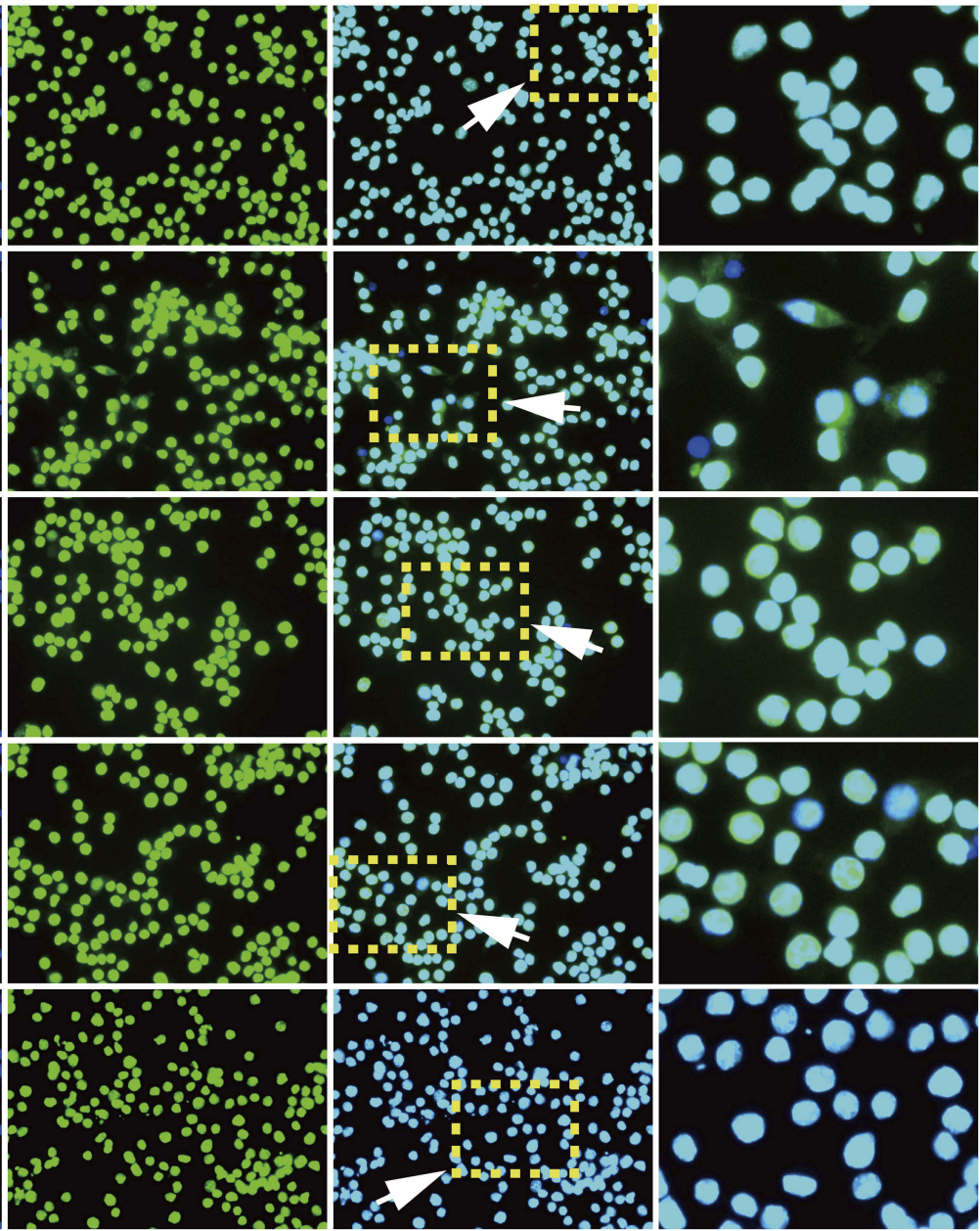
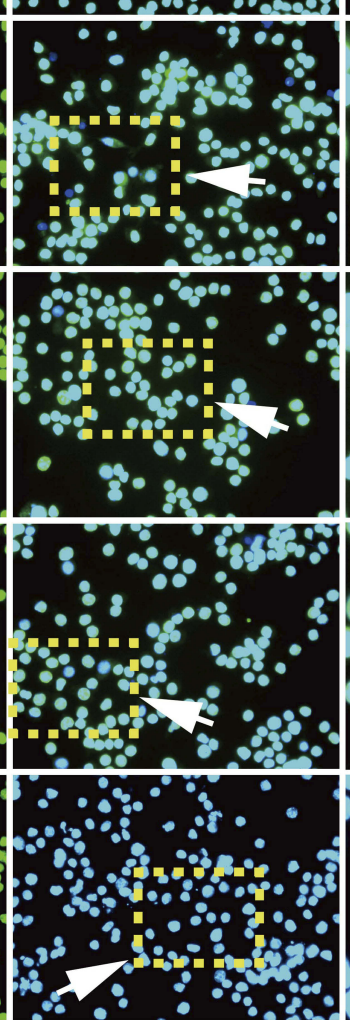
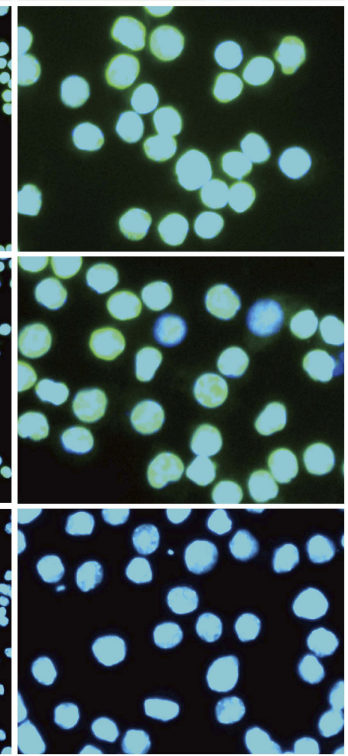

Figure 10 Effect of different formulations, including CLs-siRNA, CLs-DHA/siRNA and TAT-CLs-DHA/siRNA liposomes on nuclear translocation of HMGBI in RAW264.7 cells. Intracellular HMGBI was visualized with green immunofluorescent FITC-staining. 
A

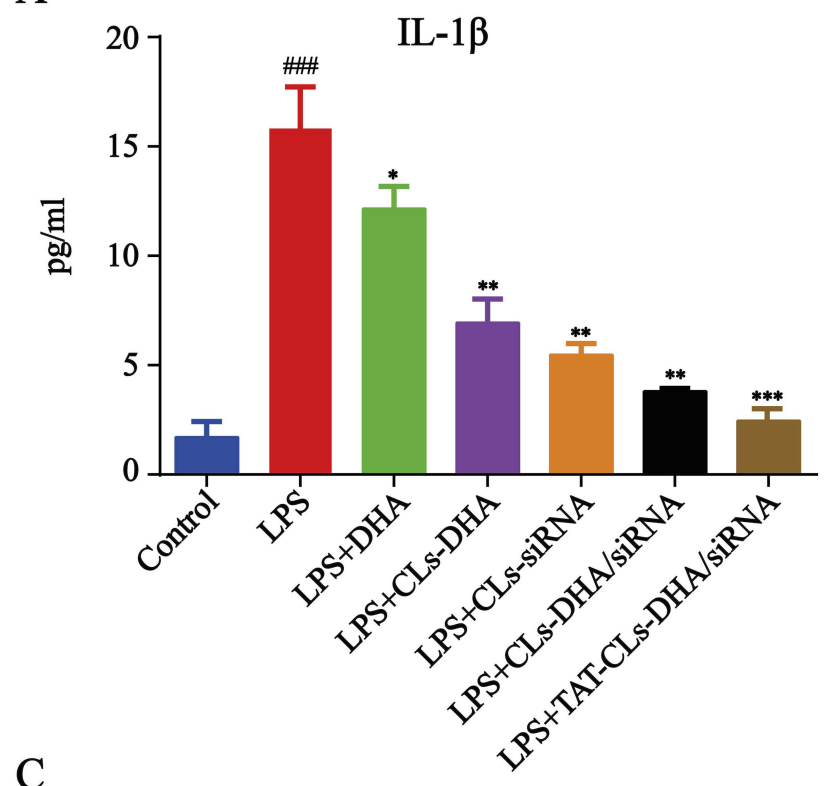

B

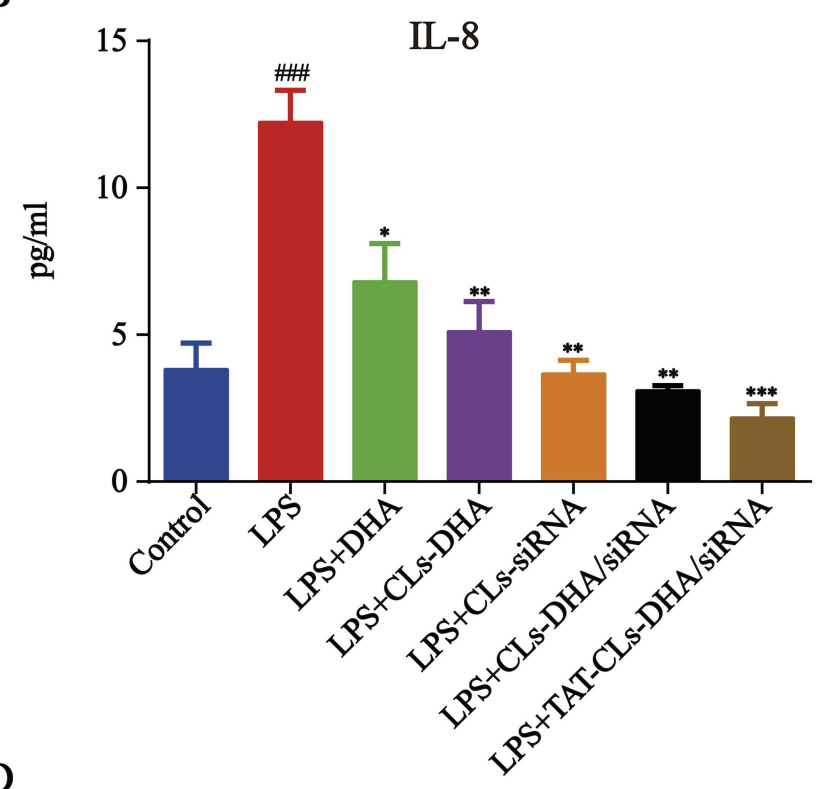

D

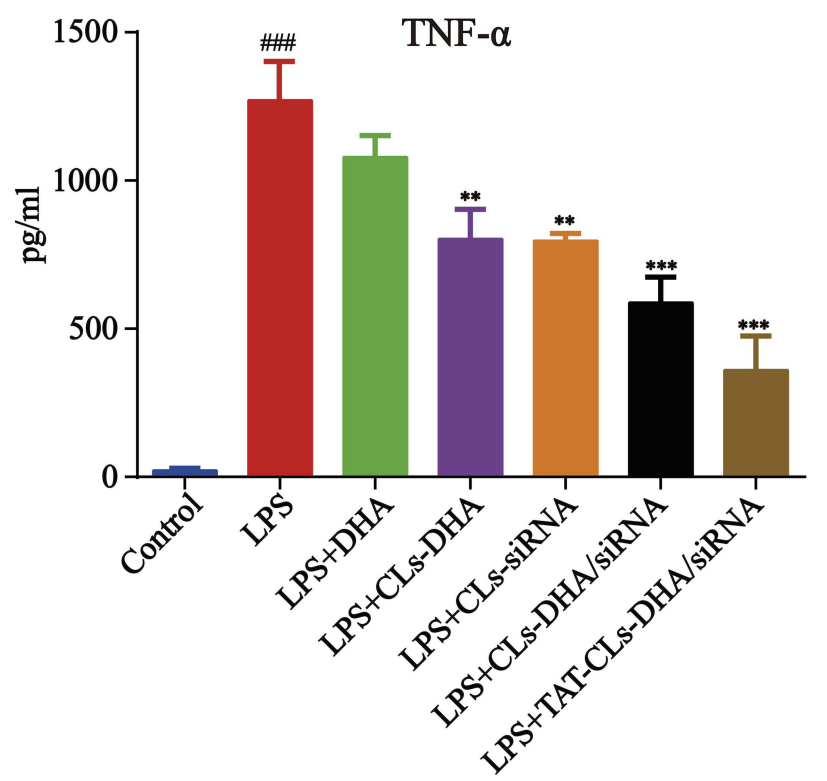

Figure II Effect of different formulations, including DHA, CLs-DHA, CLs-siRNA, CLs-DHA/siRNA and TAT-CLs-DHA/siRNA liposomes on the expression of inflammatory mediators in LPS-induced RAW264.7 cells. The DHA concentration of $20 \mu \mathrm{g} / \mathrm{mL}$ and siRNA concentration of I00 nM. (A) IL-I $\mathbf{\beta}$. (B) IL-8. (C) IL-6. (D) TNF- $\alpha$. Data represent mean \pm SD $(n>5) .{ }^{* * *} p<0.001,{ }^{* *} p<0.01$, ${ }^{*} p<0.05$ compared to LPS group. ${ }^{* \# \#}<0.001$, compared to control group.

The results demonstrated that TAT-CLs-DHA/siRNA had a much higher transfection efficiency than unmodified cationic liposomes, resulting in excellent HMGB1 gene silencing activity. After modification by the TAT peptide, the cellular uptake of liposomes was also increased significantly. A study has also demonstrated that attachment of TAT peptide to the surface of a drug carrier enhances cellular uptake of the carrier. ${ }^{34}$ We also found that the liposome carrier was almost nontoxic to cells in a certain concentration range (Figures 3-5).
MMC cell proliferation is a universal morphological manifestation of renal diseases and involved in the pathogenesis of many renal diseases. ${ }^{35} \mathrm{HMGB} 1$ expression is significantly elevated in the kidneys of LN patients and is positively associated with disease activity and renal damage. ${ }^{36}$ Previous studies have revealed that HMGB1 is a major cytokine in LN pathogenesis and that HMGB1 induces mesangial cell proliferation in mice. ${ }^{37}$ Our data showed that TAT-CLs-DHA/ siRNA significantly inhibited LPS-induced proliferation of MMC cells. When the HMGB1 gene in MMC cells was 
silenced, their proliferation was also inhibited to a certain extent, indicating that the proliferation of MMC cells is related to HMGB1 gene expression. Immunofluorescence experiments showed that TAT-CLs-DHA/siRNA inhibits LPS-induced HMGB1 translocation from nucleus to cytoplasm in MMC cells. These results were consistent with another report ${ }^{38}$ (Figure 6).

Activation of NF-кB by LPS is principally mediated through the TLR4 receptor. We used HEK-BlueTMhTLR4 cells overexpressing TLR4 to elucidate the mechanism. The results showed that TAT-CLs-DHA/ siRNA blocked LPS-induced NF-кB activity of the TLR4 signaling pathway.

HMGB1/TLR4 is crucial to promote lupus progression. To further explore the therapeutic mechanism of TAT-CLs-DHA/ siRNA, we use LPS-stimulated RAW264.7 cells producing excessive inflammatory mediators and proinflammatory cytokines to evaluate the anti-inflammatory activity of TAT-CLsDHA/siRNA. RAW264.7 is a macrophage cell line that is frequently used to study the TLR4 inflammatory pathway. ${ }^{39}$ LPS significantly stimulated HMGB1, TLR4, MyD88, IRAK4, and NF-кB gene expression. Furthermore, TATCLs-DHA/siRNA treatment downregulated the expression levels of HMGB1, TLR4, IRAK4, Myd88, and NF-kB in RAW264.7 cells. Our data validated the rationale of co-delivery of DHA and HMGB1 siRNA by HMGB1 siRNA acting on HMGB1 gene expression and DHA on the TLR4 signal pathway with an excellent synergistic effect for LN therapy (Figure 8).

LPS produces a powerful inflammatory response through activation of the TLR4, resulting in activation of $\mathrm{NF}-\kappa \mathrm{B}$ and inflammatory cytokines, including IL-1 $\beta$, IL-8, IL-6, and TNF- $\alpha .{ }^{40}$ We found that treatment of RAW264.7 macrophages with TAT-CLs-DHA/siRNA significantly suppressed LPS-induced levels of proinflammatory cytokines. The results showed a perfect anti-inflammatory effect of liposomes.

Therefore, co-delivery HMGB1 siRNA and DHA by TAT-modified cationic liposomes may be a promising treatment strategy for inflammatory diseases such as LN, and the system can be applied to other drugs and siRNAs.

\section{Conclusion}

In summary, we successfully synthesized DSPE-PEG2000TAT and constructed a new cationic liposomes delivery system to delivery HMGB1 siRNA and DHA for LN therapy. Compared to CLs-DHA/siRNA, our results indicate that the TAT peptide modified cationic liposomes had a good effect of cell membrane penetration. The complexes of TAT-CLsDHA/siRNA showed significant silencing activity and inhibit the Proliferation of MMC cells. Addictional, the TATCLs-DHA/siRNA can effectively inhibit inflammatory responses via the suppression of the HMGB1/TLR4/NF-кB signal pathway and down-regulation of inflammatory factors. But we also acknowledge the potential limitations of this research, we will carry out in vivo experiments to further confirm the efficacy of the drug and will consider it from the perspective of immunity. Our fingings not only shed light on the regulatory mechanism of TAT-CLs-DHA/siRNA antiinflammatory, but also provided potential therapeutic targets for inflammatory diseases such as lupus nephritis.

\section{Acknowledgments}

This work was financially supported by National Natural Science Foundation of China (Nos. 81773673 and 81603363) and the Key Laboratory of Ningbo, China (No. 2016A22002).

\section{Disclosure}

The authors report no conflicts of interest in this work.

\section{References}

1. Lee S-Y, Lee SH, Seo H-B, et al. Inhibition of IL-17 ameliorates systemic lupus erythematosus in Roquinsan/san mice through regulating the balance of TFH cells, GC B cells, Treg and Breg. Sci Rep. 2019;9(1):5227-5234. doi:10.1038/s41598-019-41534-1.

2. Liu J, Huang $X$, Hao $S$, et al. Peli1 negatively regulates noncanonical $\mathrm{NF}-\mathrm{\kappa B}$ signaling to restrain systemic lupus erythematosus. Nat Commun. 2018;9(1):1136-1148. doi:10.1038/s41467-018-03530-3.

3. Dall'Era M. Treatment of lupus nephritis: current paradigms and emerging strategies. Curr Opin Rheumatol. 2017;29(3):241-247. doi:10.1097/bor.0000000000000381.

4. Zhang H, Fu R, Guo C, et al. Anti-dsDNA antibodies bind to TLR4 and activate NLRP3 inflammasome in lupus monocytes/macrophages. J Transl Med. 2016;14(1):156-167. doi:10.1186/s12967-016-0911-z.

5. Kajubi R, Ochieng T, Kakuru A, et al. Monthly sulfadoxine-pyrimethamine versus dihydroartemisinin-piperaquine for intermittent preventive treatment of malaria in pregnancy: a double-blind, randomised, controlled, superiority trial. Lancet. 2019;393(10179):1428-1439. doi:10.1016/S0140-6736(18)32224-4.

6. Zhang Z, Guo M, Zhao S, Shao J, Zheng S. ROS-JNK1/2-dependent activation of autophagy is required for the induction of anti-inflammatory effect of dihydroartemisinin in liver fibrosis. Free Radic Biol Med. 2016;101:272-283. doi:10.1016/j.freeradbiomed.2016.10.498.

7. Wu Y, He S, Bai B, et al. Therapeutic effects of the artemisinin analog SM934 on lupus-prone MRL/lpr mice via inhibition of TLR-triggered B-cell activation and plasma cell formation. Cell Mol Immunol. 2016;13(3):379-390. doi:10.1038/cmi.2015.13.

8. Li WD, Dong YJ, Tu YY, Lin ZB. Dihydroarteannuin ameliorates lupus symptom of BXSB mice by inhibiting production of TNF-alpha and blocking the signaling pathway NF-kappa $\mathrm{B}$ translocation. Int Immunopharmacol. 2006;6(8):1243-1250. doi:10.1016/j.intimp.2006. 03.004 . 
9. Shi C, Li H, Yang Y, Hou L. Anti-inflammatory and immunoregulatory functions of artemisinin and its derivatives. Mediators Inflamm. 2015;2015:435713-435720. doi:10.1155/2015/435713.

10. Zhang LX, Xie XX, Liu DQ, Xu ZP, Liu RT. Efficient co-delivery of neo-epitopes using dispersion-stable layered double hydroxide nanoparticles for enhanced melanoma immunotherapy. Biomaterials. 2018;174:54-66. doi:10.1016/j.biomaterials.2018.05.015.

11. Sajeesh S, Lee TY, Kim JK, et al. Efficient intracellular delivery and multiple-target gene silencing triggered by tripodal RNA based nanoparticles: a promising approach in liver-specific RNAi delivery. J Controlled Release. 2014;196:28-36. doi:10.1016/j.jconrel.2014.09.016.

12. Cao Y, Huang HY, Chen LQ, et al. Enhanced lysosomal escape of $\mathrm{pH}-$-responsive polyethylenimine-betaine functionalized carbon nanotube for the codelivery of survivin small interfering RNA and doxorubicin. ACS Appl Mater Interfaces. 2019;11(10):9763-9776. doi:10.1021/acsami.8b20810.

13. Chen Q, Guan X, Zuo X, Wang J, Yin W. The role of high mobility group box 1 (HMGB1) in the pathogenesis of kidney diseases. Acta Pharm Sin B. 2016;6(3):183-188. doi:10.1016/j.apsb.2016.02.004.

14. Pan HF, Wu GC, Li WP, Li XP, Ye DQ. High Mobility Group Box 1: a potential therapeutic target for systemic lupus erythematosus. $\mathrm{Mol}$ Biol Rep. 2010;37(3):1191-1195. doi:10.1007/s11033-009-9485-7.

15. Xu B, Zhu YJ, Wang CH, et al. Improved cell transfection of siRNA by $\mathrm{pH}$-responsive nanomicelles self-assembled with $\mathrm{mPEG}-\mathrm{b}-\mathrm{PHis}-$ b-PEI copolymers. ACS Appl Mater Interfaces. 2018;10(26):2184721860. doi:10.1021/acsami.8b04301.

16. Zheng M, Tao W, Zou Y, Farokhzad OC, Shi B. Nanotechnologybased strategies for siRNA brain delivery for disease therapy. Trends Biotechnol. 2018;36(5):562-575. doi:10.1016/j.tibtech.2018.01.006.

17. Bi Y, Lee RJ, Wang X, et al. Liposomal codelivery of an SN38 prodrug and a survivin siRNA for tumor therapy. Int $J$ Nanomedicine. 2018;13:5811-5822. doi:10.2147/ijn.s173279.

18. Han W, Yin G, Pu X, Chen X, Liao X, Huang Z. Glioma targeted delivery strategy of doxorubicin-loaded liposomes by dual-ligand modification. J Biomater Sci Polym Ed. 2017;28(15):1695-1712. doi:10.1080/09205063.2017.1348739.

19. Alemi A, Zavar Reza J, Haghiralsadat F, et al. Paclitaxel and curcumin coadministration in novel cationic PEGylated niosomal formulations exhibit enhanced synergistic antitumor efficacy. J Nanobiotechnology. 2018;16(1):28-48. doi:10.1186/s12951-018-0351-4.

20. Devarapu S, Anders H. Toll-like receptors in lupus nephritis. $J$ Biomed Sci. 2018;25(1):35. doi:10.1177/0961203319828518.

21. Ma K, Li J, Wang X, et al. TLR $4^{+} \mathrm{CXCR}^{+}{ }^{+}$plasma cells drive nephritis development in systemic lupus erythematosus. Ann Rheum Dis. 2018;77 (10):1498-1506. doi:10.1136/annrheumdis-2018-213615.

22. Hu W, Wu S, Zhang Y, Sigdel KR, Lin Y, Zhong H. Association between Toll-like receptor 4 polymorphisms and systemic lupus erythematosus susceptibility: a meta-analysis. Biomed Res Int. 2016;2016:7842587. doi:10.1155/2016/7842587.

23. Sheng ZX, Yao H, Cai ZY. The role of miR-146b-5p in TLR4 pathway of glomerular mesangial cells with lupus nephritis. Eur Rev Med Pharmacol Sci. 2018;22(6):1737-1743. doi:10.26355/eurrev 20180314589.

24. Zhang F, Wu L, Qian J, et al. Identification of the long noncoding RNA NEAT1 as a novel inflammatory regulator acting through MAPK pathway in human lupus. J Autoimmun. 2016;75(undefined):96-104. doi:10.1007/s11515-016-1433-z.

25. Lee T, Tang S, Wu M, Song Y, Yu C, Sun K. Transgenic overexpression of anti-double-stranded DNA autoantibody and activation of Toll-like receptor 4 in mice induce severe systemic lupus erythematosus syndromes. J Autoimmun. 2010;35(4):358-367. doi:10.1016/ j.jaut.2010.07.007.
26. Musumeci D, Roviello G, Montesarchio D. An overview on HMGB1 inhibitors as potential therapeutic agents in HMGB1-related pathologies. Pharmacol Ther. 2014;141(3):347-357. doi:10.1016/j.pharmthera.2013. 11.001 .

27. Ji J, Fu T, Dong C, et al. Targeting HMGB1 by ethyl pyruvate ameliorates systemic lupus erythematosus and reverses the senescent phenotype of bone marrow-mesenchymal stem cells. Aging. 2019;11 (13):4338-4353. doi:10.18632/aging.102052.

28. Xue J, Ge H, Lin Z, et al. The role of dendritic cells regulated by HMGB1/TLR4 signalling pathway in myocardial ischaemia reperfusion injury. J Cell Mol Med. 2019;23(4):2849-2862. doi:10.1111/ jcmm.14192.

29. Huang X, Xie Z, Liu F, et al. Dihydroartemisinin inhibits activation of the Toll-like receptor 4 signaling pathway and production of type I interferon in spleen cells from lupus-prone MRL/lpr mice. Int Immunopharmacol. 2014;22(1):266-272. doi:10.1016/j. intimp.2014.07.001.

30. Xiong Y, Zhao Y, Miao L, Lin C, Huang L. Co-delivery of polymeric metformin and cisplatin by self-assembled core-membrane nanoparticles to treat non-small cell lung cancer. $J$ Controlled Release. 2016;244:63-73. doi:10.1016/j.jconrel.2016.11.005.

31. Duarte S, Faneca H, Lima M. Non-covalent association of folate to lipoplexes: a promising strategy to improve gene delivery in the presence of serum. J Controlled Release. 2011;149(3):264-272. doi:10.1016/j.jconrel.2010.10.032.

32. Liu E, Zhang M, Cui H, et al. Tat-functionalized Ag-FeO nanocomposites as tissue-penetrating vehicles for tumor magnetic targeting and drug delivery. Acta Pharm Sin B. 2018;8(6):956-968. doi:10.1016/j.apsb.2018.07.012.

33. Pescina S, Ostacolo C, Gomez-Monterrey IM, et al. Cell penetrating peptides in ocular drug delivery: state of the art. $J$ Controlled Release. 2018;284:84-102. doi:10.1016/j.jconrel.2018.06.023.

34. Moku G, Layek B, Trautman L, Putnam S, Panyam J, Prabha S. Improving payload capacity and anti-tumor efficacy of mesenchymal stem cells using TAT peptide functionalized polymeric nanoparticles. Cancers. 2019;11(4):491. doi:10.3390/cancers11040491.

35. Li XQ, Tian W, Liu XX, et al. Corosolic acid inhibits the proliferation of glomerular mesangial cells and protects against diabetic renal damage. Sci Rep. 2016;6:26854. doi:10.1038/srep26854.

36. Burbano C, Gómez-Puerta JA, Muñoz-Vahos C, et al. HMGB1 microparticles present in urine are hallmarks of nephritis in patients with systemic lupus erythematosus. Eur J Immunol. 2019;49(2):323335. doi:10.1002/eji.201847747.

37. Qingjuan L, Xiaojuan F, Wei Z, et al. miR-148a-3p overexpression contributes to glomerular cell proliferation by targeting PTEN in lupus nephritis. Am J Physiol Cell Physiol. 2016;310(6):C470-478. doi:10.1152/ajpcell.00129.2015.

38. Feng XJ, Liu SX, Wu C, et al. The PTEN/PI3K/Akt signaling pathway mediates HMGB1-induced cell proliferation by regulating

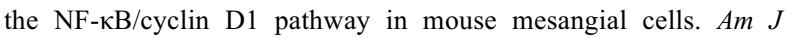
Physiol Cell Physiol. 2014;306(12):C1119-1128. doi:10.1152/ ajpcell.00385.2013.

39. Yi Y, Jian J, Gonzalez-Gugel E, et al. p204 is required for canonical lipopolysaccharide-induced TLR4 signaling in mice. EBioMedicine. 2018;29:78-91. doi:10.1016/j.ebiom.2018.02.012.

40. Mai C, Yap K, Kho M, et al. Mechanisms underlying the antiinflammatory effects of clinacanthus nutans lindau extracts: inhibition of cytokine production and Toll-like receptor-4 activation. Front Pharmacol. 2016;7:7. doi:10.3389/fphar.2016.00007 


\section{Publish your work in this journal}

The International Journal of Nanomedicine is an international, peerreviewed journal focusing on the application of nanotechnology in diagnostics, therapeutics, and drug delivery systems throughout the biomedical field. This journal is indexed on PubMed Central, MedLine, CAS, SciSearch ${ }^{\mathbb{R}}$, Current Contents ${ }^{\mathbb{B}} /$ Clinical Medicine,
Journal Citation Reports/Science Edition, EMBase, Scopus and the Elsevier Bibliographic databases. The manuscript management system is completely online and includes a very quick and fair peer-review system, which is all easy to use. Visit http://www.dovepress.com/ testimonials.php to read real quotes from published authors.

Submit your manuscript here: https://www.dovepress.com/international-journal-of-nanomedicine-journal 